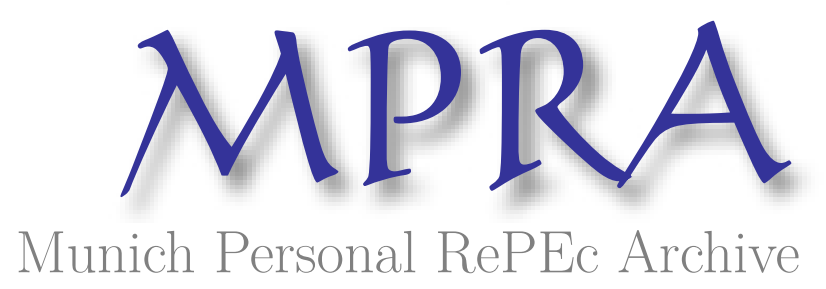

\title{
At the Root of Economic Fluctuations: Expectations, Preferences and Innovation. Theoretical Framework and Empirical Evidences.
}

Ferlito, Carmelo

INTI International College Subang, Subang Jaya, Malaysia, Institute for Democracy and Economic Affairs, Kuala Lumpur, Malaysia

1 September 2015

Online at https://mpra.ub.uni-muenchen.de/67708/

MPRA Paper No. 67708, posted 08 Nov 2015 06:11 UTC 


\title{
World Economics Association
}

Conferences, 2015

The European Crisis

2015, n. 2: $1^{\text {st }}$ September $-3^{\text {th }}$ October

\begin{abstract}
Title of paper: At the Root of Economic Fluctuations: Expectations, Preferences and Innovation. Theoretical Framework and Empirical Evidences.
\end{abstract}

\author{
Carmelo Ferlito
}

\begin{abstract}
The present paper aim to develop the Austrian Theory of Business Cycle in order to conclude that economic fluctuations are unavoidable. The conventional version of Austrian business cycle theory focuses on a temporary imbalance between natural and monetary rates of interest. When, because of the role of monetary authorities in defining the monetary rate, the two values are in a situation of imbalance, the resulting expansion stage is followed by a recession. On the other hand, if instead the expansive phase arises without any interference by monetary authorities but through re-adaptation of the productive structure to a modified structure of temporal preferences, a period of sustainable growth begins that will not be followed by a crisis. The purpose of this essay is to demonstrate, on the other hand, that because of profit-expectations and the combined action of Schumpeterian elements (imitations-speculations and the 'creation of money' by banks), even a so-called 'sustainable' boom will be affected by a liquidation and settling crisis. What distinguishes the latter situation from the conventional case of imbalance between monetary and natural rates is not the onset or otherwise of a crisis but, rather, its intensity and duration. We will define as natural an economic cycle characterised by a stage of expansion considered to be 'sustainable' in the Austrian theory but followed by an inevitable readjustment crisis. In conclusion we will try to link our theoretical conclusions with the crisis emerged in the Western world in 2007, to test the explanatory power of our theoretical framework.
\end{abstract}

\section{Keywords}

Economic Crises, Business Cycles, Schumpeter, Lachmann, Hayek, Austrian Economics, Expectations.

\section{Author(s) details}

Carmelo Ferlito

Faculty of Business, School of Accounting, Economics and Finance, INTI International University and Colleges, Subang Jaya, Malaysia.

Institute for Democracy and Economic Affairs, Kuala Lumpur, Malaysia.

E-mail: carmelo@uow.edu.au

https://newinti.academia.edu/CarmeloFerlito 
2|P a g e 


\section{INTRODUCTION. ON THE INEVITABILITY OF ECONOMIC FLUCTUATIONS}

The economic crisis that erupted in 2007 was presented, when it burst in the summer of that year, with bank and stock market collapses, as a typical financial crisis. This presentation was followed by numerous attacks on the free market and the capitalist system; sometime ideologically targeted yet often incapable of grasping the true nature of the crisis.

Subsequently, the emphasis shifted to the question of public indebtedness and, in 2013, to the single European currency, with the clear intention on the part of certain Governments to return to the possibility of devaluing a national currency in order to obtain short term export.

Nowadays, the great depression is still and mostly labelled as the $2008^{1}$ financial crisis; our analysis, on the other hand, will show that:

1. the crisis cannot be called neither financial, nor fiscal, nor even one of currency;

2. the crisis is more generally economic in nature and caused by systematic modifications of the structure of production and the allocation of employment resources.

The crisis drove Sachs $(2010,20)$ to conclude that «classic Keynesians are singing their swan song» and that «faced by a public debt crisis, the time has come to abandon short-term theories and prioritize the long-term investments needed to ensure a solid recovery». However, the great depression did not bury Keynesian economists; lead by Krugman (2008), post-Keynesian analyses did not miss the chance for asking for more government intervention, consumption stimuli and relaxation of public budget constraints ${ }^{2}$; for many of them, moreover, it was occasion to ask for further financial regulation. On the opposite side, Austrian economists took occasion to revive the Austrian Business Cycle Theory (ABCT) and to point the finger against the distortive action played by government intervention and in particular by central banks ${ }^{3}$. Neoclassical economists, instead, suffered more than the others, apparently unable to deal with the events and focusing on proposing further interest rate cut. Some of them brought out interesting reflections, questioning the mainstream approach and trying to incorporate heterodox elements in their analyses; it is the case, i.e., of Borio (2012) and Calvo (2013). Leijonhufvud (2009), illuminating as usual, presents an analysis that tries to learn from Keynes, the Austrians and Hyman Minsky.

The most interesting fact emerging from the post-crisis economic debate is maybe that, while neoclassical mainstream is suffering, old heterodox schools are trying to revive themselves and face a growing consensus. Under this perspective it emerges that the Hayek/Keynes debate is far to be defunct. Disciples of the two great economists are still on the fighting ring. Keynesians blame the free market while Austrians believe that without government induced monetary distortions crises would not arise.

According to our vision, instead, the first point to stress is that economic crises do not demonstrate the end of the capitalist economic system; on the contrary, they testify its vitality. In Ferlito $(2013,30)$ and in Ferlito $(2014 a)$ we tried to demonstrate that capitalism without fluctuations does not exist ${ }^{4}$. Indeed, we find ourselves in good company when believing that the cycle is the real form of economic development in a capitalistic system ${ }^{5}$. Marx was the first to realize this ${ }^{6}$. The same awareness is to be seen in Schumpeter's vision, influenced by Spiethoff $(1925,112)$, who concludes that «the cyclical upswings and downswings are the evolutionary forms of the highly developed capitalist economy and their

\footnotetext{
${ }^{1}$ Not only the crisis is not financial, but economic; it started to emerge in 2007. See Ferlito (2007).

${ }^{2}$ See, i.e., Roncaglia (2010).

${ }^{3}$ Among the others, see Salerno (2012), Hülsmann (2013) and Ferlito (2013).

${ }^{4}$ Huerta de Soto $(1998,468)$ points out that «[o]ne of the more curious points on which a certain agreement exists [between Marxian and Austrian analysis] relates precisely to the theory of the crises and recessions which systematically ravage the capitalist system».

${ }^{5}$ Ferlito $(2011,96)$.

${ }^{6}$ Rothbard (1969, 13).
} 
antithetic stimuli condition its progress». In turn, the Austrian economist influenced his student Paolo Sylos Labini ${ }^{7}$, and similar considerations can be found in Lachmann (1956, 110-112). Realising that the cyclic form is typical of capitalist development is also echoed in the words of another Italian economist, Marco Fanno (1931, 248-249)

Supported by the testimony of such economists, we shall bring out the motivations which drove us to the same conclusions. The core of our analysis will be the accent on the role of expectations, time preferences and innovation mechanisms. We will build our theory on the pillar of the АBCT; however, as we shall demonstrate, Mises's approach, supporting the thesis that crises happen only when monetary authorities intervene on the money supply, needs to be overcome. Austrian tradition, in fact, distinguishes between sustainable and unsustainable booms; only in the latter situation crises arise. Instead, we will argue that depressions always follow booms; the difference is only in intensity and duration. In order to support our view, we shall abandon Mises's view and use instead Hayek's perspective as starting point. Such perspective will be then integrated with key elements coming from Schumpeter and Lachmann.

\section{Methodological Intermezzo: Why Economic Theory FAiled in Forecasting THE CRISIS}

We believe that modern macroeconomics failed to understand economic fluctuations because it is prisoner of a static paradigm (general economic equilibrium), founded on econometric predictions. However, crises cannot be understood with the equilibrium framework.

First of all is thus necessary to define the nature of the object of investigation. Indeed, method is imposed by the object. This does not mean surrendering to indistinct methodological relativism but acknowledging that the phenomena of reality are complex and varied in nature.

The problem of business cycles is, of course, a dynamic one. As all economic theory, it should related to reality, to living human beings, dynamically acting in a specific time and space framework. The centre of economic analysis, in our view, is therefore human action. Dealing with real people is very different from dealing with phenomena in physics or chemistry or natural sciences in general.

In this context, it is evident that the proper perspective for studying dynamic economic phenomena is subjective. The first fact to be noted as regards studying individuals and their actions is that every gesture is guided by a principle of finality. As we shall see in the following paragraphs, it is the purpose, expectation that determines the action.

Economists are thus faced by qualitatively very well defined elements: man and reality. They should be inspired by these elements, should allow themselves to be astonished by what happens. The essence of an economist's work lies in observation of reality, without seeking to put it in a cage. Observation of reality helps identify certain dynamic trends that represent constants in human action. For example, as we have seen, the human action has a finalistic nature. That is not to say, as in the rationalist terms of the general equilibrium theory, that every subject maximizes units of utility in accordance with mathematical models. This is not what happens in reality. It is true ${ }^{8}$, however, as a dynamic trend, that man acts to achieve goals ${ }^{9}$. This sees the onset of relationships with the surroundings, people, things and complex

\footnotetext{
${ }^{7}$ See Sylos Labini (1954, 12-14) and Sylos Labini (1984, 37 and 89).

8 'True' means much more than 'rational'.

${ }^{9}$ The fragments of what he believed to be his most general happiness.
} 
society in general. Economists may certainly analyse everything that individuals do within the dynamics of enterprise in the search to attain their objectives.

This definition may seem extraneous to more familiar concepts in economics such as prices, interest rates, profit and loss, etc. But this is not the case. As we will see later, when defining their goals, people also choose the means for achieving them. In doing so, the attainment of other goals is waived and this becomes the cost of the action. If the goal is reached within the desired terms, and the satisfaction achieved is superior to the waiver, then the outcome is positive. Prices, in numerical terms, are merely a brief representation of subjective assessments and their variegated universe. In the course of their actions, individuals meet each other and, unconsciously, their assessments of ends and means meet in turn and start an unending journey of mediation. The market comes into being as a spontaneous institution, a place for relationships, where the individual choice over means and ends is challenged through inter-relationships. The system of prices emerges in this process as the mediated (objective) result of the combination of subjective assessments. This system of values allows those involved make rational economic calculations and verify, over time, whether they are attaining their goals or not.

It is possible to study these dynamics but without any pretence of planning and inclusion of attitudes within strict and formal models. Explanations are possible, only they must be of a qualitative nature. And achieving this requires the right set of tools.

In conclusion, the business of the economic scientist is possible if the search of functional relations is replaced by the desire to really understand how reality works, abandoning every constructivist temptation determined by pseudo-scientific dazzle or the possibility of perfect planning.

\section{HumAn ACTION, TIME AND EXPECTATIONS}

As we already mentioned, at the very heart of economic theory we must place human action. Two essential phenomena surround it: expectations and time. Expectations are indeed at the very root of any economic process. They are the element guiding men toward action. Action is always purposeful action. We act in order to achieve goals, which are set according to our expectations. The next step is that, in order to achieve the desired goals, human beings need to implement plans, choosing the means they believe to be appropriate in order to reach ends. What we call market process is nothing more than the interactions of human beings busy implementing plans to achieve goals. One thing must be noted. Mainstream economics treat ends and means as given; moreover, knowledge is often considered perfect and unchangeable. What happens in reality, instead, is that the content of available information is always changing and the market is precisely the place where the exchange of knowledge happens. In the flow of real time, thus, plans can be revised.

Consumers, entrepreneur-producers and resource owners are the players in the market; the latter, in turn, is where their interacting decisions, during any period of time, take place. Every player has his own content of (limited) knowledge, tastes and expectations. Depending on their knowledge, tastes and expectations, the players set up their action decisions, or plans. Since, in order to carry out their plans, individuals need to interact, it is only through interaction and in time that content of information will be modified and eventually a revision of decisions can happen ${ }^{10}$.

As defined by Kirzner, then, market process is built up by «this series of systematic changes in the interconnected network of market decisions». Therefore, it is not possible to

${ }^{10}$ See Kirzner $(1973,10)$. 
conceive a market process in the realm of perfect knowledge. The process arises precisely because of the initial ignorance of market participants and the natural uncertainty of human action. And the process can only happen during the flow of real time. With no market ignorance and no review of plans, there is no process at all. As explained by Kirzner, since from one period of market ignorance to the next one, ignorance has been somewhat reduced, market participants realize that not only should they implement more attractive opportunities but also that such attractiveness needs to be judged in comparison with the opportunities offered by competitors. This is the competitive process. When the incentive to offer more attractive opportunities stops, such process stops, too. In a situation of market equilibrium, such as the one described by the neoclassical theory of perfect competition, there is no more room for competition at all.

It becomes now necessary to explain what we means when we talk about real time. At first sight, it may seem that contemporary economic theory has included time in its historical calculations based on historic series, econometric functions and stylised models. However, such a perception of time, while perhaps being useful in the study of physical sciences, is rather unsuitable for the discovery and surprise dynamics typical of human action. It is what we may define as Newtonian time.

The Newtonian conception of time is spatialized; that is, its passage is represented or symbolized by "movements" along a line. Different dates are then portrayed as a succession of line segments (discrete time) or points (continuous time). In either case, time is fully analogized to space, and what is true of the latter becomes true of the former. (O’Driscoll and Rizzo, 1985, 82).

O'Driscoll and Rizzo (1985, 82-85) emphasise that time conceived in this way has three main characteristics: homogeneity, mathematical continuity and causal inertia. Homogeneity means that different temporal moments are simply points in space, a temporal position; nothing may happen between one moment and another. This means that homogeneous time is fundamentally static. Mathematical continuity, on the other hand, implies that time is simply a sequence of moments, which may even be different, but no change can take place endogenously. Since time is a sequence of static situations, each change must be exogenous. Causal inertia, lastly, means that nothing happens with the flow of time. There is no learning, there is no change in knowledge or adjustment of expectations. The system itself must already contain all the elements needed for it to function. It is evident such a concept lends itself poorly to representing unpredictable and dynamic human actions.

What interests us, on the other hand, is real time, a «dynamically continuous flow of novel experiences. [...] We cannot experience the passage of time except as a flow: something new must happen, or real time will cease to be» ${ }^{11}$. As described by O'Driscoll and Rizzo (1985, 89-91), the characteristics of real time are precisely to opposite to those of Newtonian time. They are: dynamic continuity, heterogeneity and causal efficacy. If we consider dynamic continuity, time must consist of memory and expectations; i.e. it is structurally related moments, past and future, through the perceptions of the individual; one cannot imagine a present without memory of the past and expectations for the future; inasmuch, all the moments in the flow of time are intimately linked and reciprocally influenced. Heterogeneity, on the other hand, means that in each successive moment the individual's perception has of the facts may be, and in fact is, different: the past, once it has occurred, becomes memory, enhancing the present and thereby also changing perception of the future; therefore, the perception of things changes from moment to moment, thereby making the characteristics of a given moment in time radically different from those of the previous moment. The direct consequence of heterogeneity is causal efficacy; the flow of

${ }^{11}$ O’Driscoll and Rizzo $(1985,89)$. 
time modifies knowledge, awareness and information, thereby expanding the creative potential of human action. Yet this is possible precisely because of acquisitions made 'beforehand' in time.

We can now introduce two more elements crucial to our analysis. They are time preferences and the inter-temporal structure of production. According to the law of time preference, «other things being equal, humans always place present goods higher than future goods on their scales of value» ${ }^{12}$; starting from this assumption, the Austrian School comes to a definition of interest rate radically opposed to that of the dominant theory ('cost of money'). We may define «the interest rate [as] the market price of present goods in terms of future goods ${ }^{13}$. It is therefore limiting and profoundly wrong to define the interest rate as the cost of money. The law of time preference does not apply only to the capital market. It should be extended to the entire economic system, where the natural rate is consequently that rate of equilibrium which reflects the temporal preferences of economic agents. It is thus possible to define an interest rate for the economic system, which measures the more general structure of time preferences. As regards consumers, it defines the relationship between consumption and saving. In the case of entrepreneurs linked to investments, it measures the propensity towards the future, that desire to undertake long-term projects in the investment goods sector that makes the production structure more circular and the production period longer, compared to investments in consumer goods and investments having a faster realisation cycle.

In a future-oriented system, consumers are more savings-oriented, thereby encouraging the accumulation of loanable funds that can be used by entrepreneurs in long-term projects. A present-oriented society, in contrast, has a greater propensity towards consumption on the consumer side, while investors do not lengthen the production process. Situations of equilibrium may exist in a system with a high time preference as on the contrary. It is not the sum of one of the aggregates that defines this equilibrium but the possibility for time preferences to come together through the free exercise of the entrepreneurial function that each person enacts in relationships with other people in the process of satisfying needs of various kinds.

The level of equilibrium for a combination of time preferences is measured by the natural interest rate, which in turn corresponds to a well-defined structure of the production process. The key element that, by fuelling a modification of the inter-temporal structure of production, generates a cycle of expansion and crisis is given by a change in level of the natural rate. According to the traditional Austrian perspective, if the mutation of the natural interest rate reflects a change in time preferences, this generates a positive expansive cycle, which will not be followed by a painful crisis (and we will seek to demonstrate, on the other hand, that a readjustment crisis is inevitable). Conversely, if the rate - rather than settling in response to interaction on the free market of entrepreneurial action of different individuals - is set by central planning authorities which follow precepts of monetary policy or political motivations, the expansive cycle that will be followed by monetary expansion will generate a crisis. In fact, there will have been no change in the natural rate and no change in time preferences; the change generated in the structure of production will be the outcome of a false signal, the manipulation generated by monetary authorities.

To summarize: expectations generate action plan, who are carried out in time and eventually revised in order to cope with modified information, which, in turn, can force expectations to change. Expectations define also the time preference of an economic system; action plans set the intertemporal structure of the production process, which, as a process, is subject to a continuous revision. In any moment, the time preference of the system is a

\footnotetext{
${ }^{12}$ Huerta de Soto $(2000,50)$

${ }^{13}$ Huerta de Soto $(2000,50-51)$.
} 
measured by what the Austrian tradition, following Wicksell, calls the natural interest rate, defined as the price of present goods in terms of future goods. The natural interest rate, therefore, is generated by expectations too.

Expectations are consequently the hallmark of a society made of real players which, starting precisely from them, form their own plans for the future, meeting and modifying knowledge and the plans themselves. This generates the kaleidic society ${ }^{14}$, "a society in which sooner or later unexpected change is bound to upset existing patterns, a society "interspersing its moments or intervals of order, assurance and beauty with sudden disintegration and a cascade into a new pattern" $\gg{ }^{15}$. The kaleidoscopic world is a world where change is constant.

In a kaleidoscopic society, moreover,

the equilibrating forces, operating slowly, especially where much of the capital equipment is durable and specific, are always overtaken by unexpected change before they have done their work, and the results of their operation disrupted before they can bear fruit. [...] Equilibrium of the economic system as a whole will thus never be reached. (Lachmann, 1976, 60-61).

From what we saw so far we can conclude that expectations are not something "up in the clouds", to be treated as exogenous data; without them, there is no economic activity as such; it is starting from expectations that every decision is taken with the intention of making a profit or achieving personal satisfaction. However, these attempts emerge in a context of imperfect knowledge and an unexpected and unpredictable future ${ }^{16}$. Uncertainty is a key element in the economic process; we cannot even imagine that opportunities for profit will arise outside a context of uncertainty and disequilibrium ${ }^{17}$. In fact, without uncertainty, all occasions for profit would have already been exhausted; in an uncertain context, on the other hand, entrepreneurs who make the best forecasts or people who, for various reasons, best fulfil their expectations and plans, enjoy an advantage created precisely by the fact of knowing better how to move in such a context, how to 'imagine the future better'.

The main features of true uncertainty «are the inherent unlistability of all possible outcomes resulting from a course of action, and the complete endogeneity of the uncertainty» ${ }^{18}$. Inasmuch, if uncertainty is endogenous to the system, an intrinsic feature, it cannot but originate a constantly changing system, in which human action is essentially guided by expectations: expectations determined by preferences, that in turn generate any kind of action. Such action is intrinsically uncertain, in that nothing, a priori, ensures that such expectations will be realized.

The accumulation of knowledge merely changes the uncertainty ${ }^{19}$. The information content is not complete, only larger. Aspects affecting the pursuit of action have changed but are not complete. The outlines on the horizon, and consequently the uncertainty in relation to the complete form, are different. It is therefore clear that the theoretical bridge between preferences and action is made of expectations: desires as regards the future and the scenarios awaiting us take place, determining our possibility for action.

It is evident that expectations cannot be considered, as in neoclassical theory, as a static element fixed at the beginning of the match and then unchangeable until the final result is achieved. On the contrary, since human action is a dynamic process that unfolds over time,

\footnotetext{
${ }^{14}$ See Shackle (1972, 76-79).

15 Lachmann $(1976,54)$

${ }^{16}$ See Lachmann (1982).

${ }^{17}$ Rizzo $(1979,10)$.

${ }^{18}$ O’Driscoll and Rizzo $(1985,100)$.

${ }^{19}$ O’Driscoll and Rizzo (1985, 102-103).
} 
the set of information available to players constantly changes, bringing about a continual modification of expectations, objectives and plans.

\section{At the Origin of Economic Fluctuations: The Intertemporal Structure of PREFERENCES}

Economic fluctuations are related with the modification of the intertemporal structure of preferences. At any given time, a time preference structure is matched by a production structure, i.e. a heterogeneous set of combinations of production factors, organized by human creative and entrepreneurial action in order to carry out processes that, over time, generate an output. This output should meet a demand defined by the structure of time preferences. This structure is reflected in an interest rate that, in turn, expresses the magnitude of the preference of economic agents for present goods compared to future goods.

The central point is the distortion of the production structure defined by the system of preferences $^{20}$, and the reasons behind such a modification. The system of time preferences is determined by the expectations of players on the market who, following their own expectations, seek to implement plans to achieve them. In a free market system, this mechanism of action takes place through the meeting of different subjects who in the process acquire new information and change their expectations. We are therefore witnessing a gradual and continuous process of re-adaptation of plans, in a natural effort to ensure that their realization 'meets' the realization of the plans of others.

\subsection{The unsustainable boom}

The typical situation taken in account by the ABCT (Mises) is when a natural rate is flanked by a monetary rate set by a central authority. In this scenario, the signal role played by the monetary rate overpowers that of the equilibrium rate, because it is immediately publicized and more visible to the players on the market: it 'anticipates' the discovery mechanism typical of the market, it creates a wall between supply a demand. The monetary rate, inasmuch, becomes one of the essential engines driving expectations and the subsequent formation of plans. A difference between the natural rate and the monetary rate, by disorienting certain agents, may therefore modify the structure of production but without this change reflecting a parallel change in time preferences. Or, another possibility is that the monetary rate may not follow a unilateral change in preferences, thereby interfering with the process of adaptation by the economic system whose own preferences have not changed.

Let us now assume starting from a situation of equilibrium, a hypothetical starting point ' 0 '. We have a natural rate that reflects the meeting of time preferences and a production structure organised accordingly. Let's also suppose that the monetary rate set by central authorities is the same as the equilibrium rate. In this scenario, a disequilibrium between monetary rate and equilibrium value, whereby the former is at a value lower than the second, thereby prompting entrepreneurs to lengthen the production process, may arise in two ways. The first and most immediately intuitable hypothesis is that the central authorities cut the monetary rate in the belief that lowering the interest rate sets in motion an expansion cycle without negative repercussions. In such a scenario, central bank is misleading the profit expectations of entrepreneurs, wrongly informing them that new resources are available for investments. Therefore, entrepreneurs consider it is more convenient to invest in long-term projects; however their choices are wrongly guided a false signal, which, in 'hiding' the

${ }^{20}$ Hayek $(1929,123)$. 
natural rate, does not allow the system to activate the necessary counter-measures to the resurgence of natural tendencies towards equilibrium typical of a regime of freedom of entrepreneurial action. Entrepreneurs, following interest rate manipulation, become more future-oriented, although more savings are not generated; consequently, available resources are fictitious and time preferences are changed unilaterally, leading to a disequilibrium in inter-temporal preferences; future-oriented investors and present-oriented consumers (or not as future-oriented as entrepreneurs). A change in time preferences always happens unilaterally, but when only the natural interest rate plays a role this change can be communicated to the other side of the market. The monetary interest rates does not allow the natural one to play is information transmission role.

Yet the situation whereby the monetary interest rate is below the natural rate may also occur without the intervention of central banks. In fact, the natural rate can be pushed upwards by expanding profit expectations. Entrepreneurial action, while always seeking results, may be also determined by so-called sentiment, the inkling that certain initiatives might be profitable. In this situation, entrepreneurs become future-oriented, raising the interest rate level and pushing demand for funds to begin the longer-term production processes.

It is an apparently unimportant difference in exposition which leads one to this view that the Monetary Theory can lay claim to an endogenous position. The situation in which the money rate of interest is below the natural rate need not, by any means, originate in a deliberate lowering of the rate of interest by the banks. The same effect can be obviously produced by an improvement in the expectations of profit or by a diminution in the rate of saving, which may drive the 'natural rate' (at which the demand for and the supply of savings are equal) above its previous level; while the banks refrain from raising their rate of interest to a proportionate extent, but continue to lend at the previous rate, and thus enable a greater demand for loans to be satisfied than would be possible by the exclusive use of the available supply of savings. (Hayek, 1929, 147).

There can be many kinds of reasons for this.

New inventions or discoveries, the opening up of new markets, or even bad harvests, the appearance of entrepreneurs of genius who originate 'new combinations' (Schumpeter), a fall in wage rates due to heavy immigration; and the destruction of great blocks of capital by a natural catastrophe or many others. We have already seen that none of these reasons is in itself sufficient to account for an excessive increase of investing activity, which necessarily engenders a subsequent crisis; but that they can lead to this result only through the increase in the means of credit which they inaugurate. (Hayek, 1929, 168).

Even in this case, however, changes to preferences take place unilaterally. If, in the presence of a monetary rate, central banks do not realign the latter towards the equilibrium level in order also to encourage savers themselves to become more future-oriented by increasing saving amounts, the structure of preferences will remain disproportionate and the new inter-temporal production structure will reflect such an imbalance. In this case, therefore, expectations change before the intervention of central banks. In this case, it is not monetary manipulation that plays the key role capable of altering the system of preferences by discoordinating plans and the structure of production. In the first situation, the crucial role is given by the manner and direction in which monetary expansion influence expectations. In the second case, on the other hand, expectations themselves divert the system away from equilibrium.

Changing expectations, caused by (case 1) or the cause of (case 2) a monetary rate below its natural level, is - on closer inspection - a natural part of the entrepreneurial instinct emphasized by Schumpeter. The analysis of the entrepreneurial role (innovation) as a fundamental element in initiating an expansion cycle, implemented in an organic way by Schumpeter, is entirely coherent with our analysis. We are explicitly discussing the concept 
of expectations: entrepreneurs see opportunities for profit and take advantage of them, i.e. they have positive expectations, or, otherwise, they are future-oriented and ready to make the production process more roundabout. Some are prepared to take risks on real innovations that can create a competitive advantage for them. Others by merely imitating on the wave of enthusiasm. Still others by launching poorly grounded economic initiatives.

Let's return now to our analysis and the disequilibrium between natural and monetary rates. The situation consideration therefore encourages the onset of major investments in production assets, or capital goods, whereby the economy becomes, in general, more capitalintensive, i.e. the production period is extended ${ }^{21}$.

The cardinal point of the theory is the difference created between entrepreneurial decisions and consumer choices ${ }^{22}$. In the situation in question, the funds available for investments initially do not correspond to the amount of savings. In fact, an artificially low monetary rate corresponds, on the capital market, to a higher availability of money because it translates into lower interest payable on investments.

In general it is probably true to say that most investments are made in the expectation that the supply of capital will for some time continue at the present level. Or, in other words, entrepreneurs regard the present supply of capital and the present rate of interest as a symptom that approximately the same situation will continue to exist for some time. (Hayek, 1933, 142).

What Hayek says is true, and the central role of expectations is resumed. Yet, all the more, the indicator on which entrepreneurs base their choices actually does not reflect any current propensity among consumers to $\mathrm{save}^{23}$. In this way, the proportion in which producers decide to differentiate production between products for the immediate future and those for the longer term (inter-temporal production structure) does not reflect the way in which consumers intend to divide their income between savings and consumption ${ }^{24}$. It is evident that sooner or later and disequilibrium in time preferences, which is reflected in an intertemporal production structure, will arise and the typical form will be the frustration of the expectations of one of the two groups ${ }^{25}$.

So, while entrepreneurs invest in new processes for the production of capital goods, savers are frustrated in their desire to consume, because what they want is not being produced. The forced saving ${ }^{26}$ phenomenon thereby comes about, i.e. - as a consequence of the fact that production resources were diverted from sectors close to consumers - there is a gradual reduction in the production of consumer goods and therefore an involuntary limitation of consumption ${ }^{27}$.

The entrepreneurial impetus towards new investments, on the other hand, initially involves an increase in raw material prices and consequently of the capital goods produced with them ${ }^{28}$. And the impetus must be considered as particularly violent in that the wave of the first innovative entrepreneurs is joined by the pressure of imitators described by Schumpeter, who grasp profit opportunities only in a second stage and attempt to benefit by following the 'fashion'. On a closer look, imitative speculation waves are typical of every boom stage described in history.

\footnotetext{
${ }^{21}$ Hayek (1931, 35-36).

${ }^{22}$ Hayek (1933, 143-148).

${ }^{23}$ Hayek $(1933,144)$.

${ }^{24}$ Hayek $(1933,144-145)$.

${ }^{25}$ Lachmann $(1943,69)$ and Hayek $(1933,145)$.

${ }^{26}$ See Hayek (1932). See also Huerta de Soto (1998:409-413).

${ }^{27}$ Kurz (2003:191) and Hayek (1933, 145-146).

${ }^{28}$ It is evident that this upsurge, during the expansion phase of the cycle, causes the prices of raw materials and capital goods to increase more than the prices of consumer goods (Hayek, 1939, 29).
} 
At the same time, demand for labour increases, and is attracted towards the new investments, with relative wages: this leads in turn encourages demand for consumer goods and prices in this sector also increases. And it is therefore evident that the increase in nonmonetary income will not matched an increase in real incomes, because of the inflationary effect exerted by unsatisfied demand for consumer goods.

This increased intensity of the demand for consumers' goods need have no unfavourable effect on investment activity so long as the funds available for investment purposes are sufficiently increased by further credit expansion to claim, in the face of the increasing competition from the consumers' goods industries, such increasing shares of the total available resources as are required to complete the new processes already under way. (Hayek, 1933, 147).

Nevertheless, in order to be sustained, this process requires credit expansion without respite - which would bring about a cumulative increase in prices that sooner or later would exceed every limit. The conflict seems to be evident when demand for consumer goods exceeds in terms of absolute value the funds available for investment. At this point, the interest rate cannot but rise, frustrating demand for capital goods precisely when their price has also risen ${ }^{29}$. A considerable part of the new plant installed, designed to produce other capital goods, remains unused since the further investments required to complete production processes cannot be made ${ }^{30}$. As a result, in an advanced stage of the boom, growth in demand for consumer goods brings down demand for capital goods ${ }^{31}$.

As we have seen, such a situation can may actually occur even without monetary manipulation but as a result of growing profit expectations which, since the monetary rate is not allowed to rebalance itself with the natural level, cannot find counterparts in realignment with the value of the savings.

Inasmuch, the economy is unable to sustain production oriented over and above its possibilities. Sooner or later, it is realised that an increase in wages is cancelled by growing inflation. In addition, demand for capital goods runs out, taking with it the over-production in the particular sector and it is here where problems arise. Many economic initiatives set up through excessive reliance on credit cannot be completed, although the debts still have to be paid. Many companies have to be expelled from the system. Capital is scarce and banks raise interest rates. A period of adjustment and return to equilibrium begins, only it has aspects of a depression.

\subsection{The Sustainable Boom}

According to the traditional version of the ABCT, the wave dynamics typical of capitalism would be sustainable if, in typical situations of bright expectations, players were free to learn through interaction with each other and allow their choices to be judged on the market. Without the interference of a monetary rate, players would be forced to seek, on the market, to what extent their expectations are in line with those of other agents and therefore this would allow plans to be realised. The natural rate, although unknown as a magnitude, is dynamically given by time preferences, thereby generating a production structure in keeping with such preferences. The system would move and settle continuously. In this way, every change in the structure of production would be the adaptation to a change in time preferences, a dynamic adaptation: if profit expectations rise, pushing the natural rate upwards, the new production structure cannot begin to change until the new natural rate also convinces

\footnotetext{
${ }^{29}$ As the rate of interest increases, the rate of profit declines (Hayek, 1939, 31).

${ }^{30}$ Hayek $(1933,148)$.

${ }^{31}$ Hayek $(1939,31)$.
} 
consumers to change their attitudes; at the same time, it is likely that not all the intense demand for new investments will be 'met' from new savings, so that the natural rate will tend to stabilise at a lower point than the initial expansionist impetus generated by entrepreneurial expectations. Demand and supply mechanism will generate, through information transmission, the new price able to link expectations of investors and consumers.

As can be seen, the situation is very different if there is a monetary rate capable of disguising the real strength of natural rate. And it is precisely the discrepancy generated between the natural and monetary value of the interest rate that tells us how long and painful cyclical dynamics will be ${ }^{32}$.

In a system where there is no central bank, there is no monetary interest rate imposed by central authorities. In such as system, in which an effective free market would operate, there would simply be the natural equilibrium rate, capable of measuring the structure of time preferences. This means that price system as information transmission mechanism can actually work. What happens in the event of a unilateral modification on time preferences, such as an increase in the savings rate? This is the situation in which consumers become more future-oriented. It is thereby evident that a conflict arises between the time preferences of consumers and those of investors. Yet this also means that the equilibrium rate moves downwards, in an attempt also to orient the plans of entrepreneurs towards the future, who would therefore be encouraged to change the structure of the production process, starting with investments in more capital-intensive goods: the new lower interest rate is 'informing' investors that new resources are available for long-term investments. These investments will be financed precisely with the new savings. The new equilibrium rate, the only signal for players on the market, allows entrepreneurs to modify their expectations and plans; it informs them that new resources are available and that investments can be implemented profitably. The entrepreneurial instinct, typically Schumpeterian and also emphasized by Spiethoff, thereby allows the re-adaptation of expectations in order to harmonize time preferences.

Consequently, without the interference of the central bank, the natural equilibrium rate (a price generated by the interaction of supply and demand and not imposed by central banks) allows the production structure to adapt to the new system of time preferences. The profit expectations of entrepreneurs, encouraged by the lower rate of interest, are not frustrated because they find a counterpart in the different attitude among consumers, who are now less oriented towards immediate consumption. In this case, the elongation of the productive structure, the expansion cycle, is sustainable because the free interaction of players does not encounter interference and plans can be adapted. This does not mean that, in the process of adaptation, errors are not encountered errors or that certain expectations will be frustrated. Preferences adaptation is a process that takes place in real time, not instantly. However, conditions exist whereby free transmission of information helps one to learn from mistakes and rearrange plans in line with the new situation. And the scenario itself will be continually changing. The re-adaptation process does not take place 'once and for all'; it is a continuous and never tamed process. Nonetheless, it can be implemented in a balanced manner only if the natural rate, generate by the demand-supply interaction, the only signal (price) for the players, i.e. if divergent signals are not introduced from the outside which may wrongly guide decisions and make the discoordination of preferences perpetual, thereby preventing the free inter-temporal coordination mechanism of plans.

In short, a growth path is generated when time preferences change on a global scale. And this is only possible, according to the Austrian theory, if the central element measuring time preferences - the interest rate - is left free to set itself on the market through the interaction

${ }^{32}$ Hayek $(1929,183)$. 
of individuals freely exerting their entrepreneurial function in the process of meeting their needs.

\subsection{Is Sustainable Boom Actually Sustainable?}

In all the cases analysed so far, we could notice how the boom is always generated by a moving toward the future of the intertemporal structure of the preferences. Changing expectations can occur from the consumer side or from the entrepreneur side. What matters is that the result is a lengthening of the structure of the production: more roundabout production processes are started by the entrepreneurs. These new investment are what are called innovations in the Schumpeterian approach; they generate development ${ }^{33}$, or the «spontaneous and discontinuous changes in the channel of the circular flow and [the] disturbances of the centre of equilibrium» ${ }^{34}$.

It is time to implant some Schumpeterian elements into the theory we sketched so far. This will help us to understand why economic crises are unavoidable. Let us assume that we set off from a situation of perfect static equilibrium in which assumptions of perfect competition, constant population, lack of savings and everything needed to meet the requirements of the circular flow ${ }^{35}$ (Schumpeter calls such a situation of equilibrium the 'theoretical standard' ${ }^{36}$ ) hold true. It is also assumed that, in the capitalist society model, there will always be the possibility of new combinations and people capable and willing to implement them (their motivation is the prospect of profit).

Some people, then, conceive and work out with varying promptness plans for innovations associated with varying anticipations of profits, and set about struggling with the obstacles incident to doing a new and unfamiliar thing $[\ldots]$ we suppose that he founds a new firm, constructs a new plant, and orders new equipment from existing firms. The requisite funds he borrows from a bank. On the balance acquired by so doing he draws, either in order to hand the checks to other people who furnish him with goods and services, or in order to get currency with which to pay for these supplies. [...] he withdraws, by his bids for producers' goods, the quantities of them he needs from the uses which they served before.

Then other entrepreneurs follow, after them still others in increasing number, in the path of innovation, which becomes progressively smoothed for successors by accumulating experience and vanishing obstacles. (Schumpeter, 1964, 133-134).

What we note from the foregoing excerpt? Firstly, Schumpeter assumes that entrepreneurs immediately spend their deposits, except for a minimum reserve. Secondly, since there are no unused resources at the outset (given the circular flow hypothesis), the prices of production factors will increase, as well as monetary incomes and the interest rate. Thirdly, revenue will also increase, in line with the expenditure by entrepreneurs in investment goods, alongside those of workers, momentarily employed with higher wages, and those of everyone receiving all those higher payments ${ }^{37}$. However, up to this point, it is legitimate to assume that there has not yet been an increase in production ${ }^{38}$. This is what happens until the plant of the first entrepreneur begins to run $^{39}$.

\footnotetext{
${ }^{33}$ Development in Schumpeter's point of view must be absolutely distinguished from growth, which can also occur even a stationary condition, in being distinguished by the absence of structural changes. In this regard, see also Lachmann (1940, 271).

${ }^{34}$ Schumpeter $(1911,65)$

35 Schumpeter (1964, 132-133).

${ }^{36}$ Schumpeter $(1964,29-38)$.

${ }^{37}$ Schumpeter $(1964,134)$.

${ }^{38}$ Schumpeter $(1964,135)$.

${ }^{39}$ Schumpeter $(1964,136)$.
} 
Then the scene begins to change. The new commodities - let us say, new consumers' goods - flow into the market. They are, since everything turns out according to expectation, readily taken up at exactly those prices at which the entrepreneur expected to sell them. [...] A stream of receipts will hence flow into the entrepreneur's account, at a rate sufficient to repay, during the lifetime of the plant and equipment originally acquired, the total debt incurred plus interest, and to leave a profit for the entrepreneur. [...] the new firms, getting successively into working order and throwing their products into the market of consumers' goods, increase the total output of consumers' goods [...]. (Schumpeter, 1964, 136).

Such new goods, according to Schumpeter, enter the market too quickly to be absorbed smoothly. In particular, the old enterprises and the pursuers have several possible scenarios before them, but there is no fixed rule: some become part of the new scenarios, others close because they are unable to adapt, others still seek rationalization ${ }^{40}$. However, the competitive advantage of the driving company tends to fade, since, as the products progressively come on to the market and the debt repayments quantitatively increase in importance, entrepreneurial activity tends to diminish to the point of disappearing altogether ${ }^{41}$. As soon as entrepreneurial impetus loses steam, pulling the system away from its previous area of equilibrium, the system embarks on a struggle towards a new equilibrium. The initial outline of a cyclic pattern can be seen ${ }^{42}$.

Each of those two phases is characterized by a definite succession of phenomena. The reader need only recall what they are in order to make the discovery that they are precisely the phenomenon which he associates with "prosperity" and "recession": our model reproduces, by its mere working, that very sequence of events which we observe in the course of those fluctuations in economic life which have come to be called business cycles and which, translated into the language of diagrams, present the picture of an undulating or wavelike movement in absolute figures or rates of change. (Schumpeter, 1964, 142).

The following is the reasoning that leads to the second approximation of the cycle. If innovations are incorporated into new plant and equipment, spending on consumer goods will increase at least as fast as spending on capital goods. Both will expand starting from those points in the system where they exerted the first impact and will create that set of economic situations which we call prosperity. Two phenomena arise here: firstly, old businesses will react to this situation and, second, a number of them will speculate on it. Those who seek to take advantage of the situation, by speculating, act on the assumption that the rates of change they observe will continue indefinitely; such an attitude anticipates prosperity, causing a boom $^{43}$. At this point, transactions join the picture that, in order to become possible, assume an expected or effective increase in prices. This is how, in the cyclic process, a secondary wave comes into play, the effects of which overlap those of the primary wave ${ }^{44}$. The outcomes of the new wave are also more visible than the first wave.

Even in secondary prosperity, the break is induced by a turning point in the underlying process. Any state of prosperity, however ideally limited to essential primary processes, involves a period of failures that, in addition to eliminating enterprises that are obsolete beyond any chance of re-adaptation, also gives rise to a painful readjustment process of prices, quantities and values, as the framework of a new system of equilibrium progressively emerges $^{45}$. Secondary prosperity even sees risky, fraudulent or in any case unlucky initiatives take shape that are unable to cope with the recession (entrepreneurs defined as imitators and speculators, who simply follow the situation of change). The speculative position involves

\footnotetext{
${ }^{40}$ Schumpeter (1964, 137-138).

${ }^{41}$ Schumpeter $(1964,138)$.

42 Schumpeter $(1964,142)$.

${ }^{43}$ Schumpeter $(1964,150)$.

${ }^{44}$ Schumpeter $(1964,151)$.

${ }^{45}$ Schumpeter (1964, 153-154).
} 
many unsustainable elements, which even a minimal deterioration of the value of collateral elements will cause to fall. Inasmuch, a great deal of the day-to-day business and investments will suffer a loss as soon as prices fall, as they undoubtedly will in view of the primary process. A portion of the debt structure will also collapse. If panic and crisis prevail in this case, further adjustments become necessary: values fall and every fall brings with it yet another fall. For a certain time, the pessimistic expectation may play a decisive role, even if it subsequently does not hold up unless substantiated by objective factors ${ }^{46}$.

A cyclical pattern with four stages is consequently outlined (remember that first approximation only included prosperity and recession): prosperity, recession, depression, recovery.

For our purposes, it is vital to emphasise the characteristic element of secondary prosperity: imitations and their role in further swelling the growth process. As acknowledged by Lachmann $(1986,15)$, perhaps the most Schumpeterian of the Austrians, a «competitive process taking place within the market for a good consists typically of two phases, and in it the factors of innovation and imitation may be isolated as iterative elements» ${ }^{47}$. The expansion stage of the cycle is always characterised by the elongation of the production structure - an elongation that occurs because of investments usually associated with a specific sector of assets, i.e. the one linked with growing profit expectations, in turn stimulated by a certain kind of credit policy or change in time preferences. The success of the first investments, when the liquidation process is still not on the horizon, modifies information and the expectations of many other subjects, attracting imitators who additional investments, usually financed by credit, contribute towards intensifying the magnitude of expansion.

\section{THE INEVITABILITY OF CRISES. THE NATURAL CYCLE}

Now we shall attempt to demonstrate how crisis is a consequence of all stages of growth and how sustainable and artificial booms are not distinguished by the onset of depression but by its intensity and duration. Inasmuch, in our view, even in the case of 'healthy' expansion, the growth stage will be followed by a process of resettlement (crisis). This is because - even for sustainable development - positive profit expectations, once the cycle has been set in motion, facilitate the appearance of speculative-imitative initiatives that, at a given point, must be liquidated in order to 'normalize' the progress of growth. What distinguishes sustainable development from an artificial boom is not the emergence of a crisis; the difference lies in the nature of the crisis and its intensity.

The crucial elements in our analysis, therefore, are expectations and the imitative process. As we have seen, Hayek $(1929,147)$ recognised the central role of expectations as early as 1929, when he emphasised profit expectations as the driving force behind entrepreneurial preferences, with the possibility of entrepreneurs becoming more future-oriented and thus shifting the equilibrium interest rate upwards.

Profit expectations are a key element in both the Hayekian vision of sustainable growth and in the opposite case. We will use them to describe the emergence of imitations and secondary expansion, then followed by a crisis. It is now time to see how the so-called sustainable growth in Austrian theory turned, in our view, into the natural cycle ${ }^{48}$.

In the ideal situation where the monetary rate does not exist (nor the Central Bank), a lengthening of the production period, with the emergence of capital-intensive investment

\footnotetext{
${ }^{46}$ Schumpeter $(1964,154)$.

${ }^{47}$ See also Lewin $(1997,15)$.

${ }^{48}$ See Ferlito (2014a).
} 
processes, is in fact possible when either consumers or investors become more futureoriented. If consumers are the first to change their preferences, this will take the form of growing savings followed by a decrease in the natural rate of interest, in order to attract investors to use those resources for more roundabout investments. If, on the other hand, entrepreneurs are the first to push towards lengthening of the production structure, the natural rate will rise in order to attract savers in the same direction, thereby providing necessary resources for new investments. In both cases, the natural rate is driven by a change in the structure of temporal preferences, in turn generated by different expectations. What follows is a process of sustainable development.

The role of business expectations in generating capital-intensive investments is also emphasized by Schumpeter, as is already well-known. We also saw earlier how Hayek refers explicitly to Schumpeter in highlighting the innovative and investment process that follows positive profit expectations. In this process of expansion, in accordance with the traditional version of the АВCT, the aspects needed to generate a crisis do not arise.

However, observation of reality leads us to emphasize, following Schumpeter and Lachmann, that the first wave of investments it is always followed by a secondary wave of imitations and speculations. As analysed above, the pace of economic growth becomes particularly sustained when the primary wave of entrepreneurial investments is joined by a stage of secondary growth encouraged by the copy-cat instincts of imitators in search of profit and driven by 'fashion'. Why are imitations inevitable? This is what we have already seen as regards Lachmann's vision of capitalist development characterized by innovation and imitation. Keeping faith with subjectivism and the role of expectations, it is easy to imagine how the success of entrepreneurial initiatives is readily followed by imitators looking for success within what at first sight always seems to be a period of growth destined never to end. The primary stage of growth is characterised by investment set in motion by a limited number of entrepreneurs - those who are able to seize opportunities that go unnoticed by most people and therefore the first to change their expectations (Schumpeterian entrepreneurs). The secondary stage is characterized by the appearance on the market of an exceptional number of imitators, driven by profit expectations arising from observing the ongoing of the boom set in motion by the first innovative entrepreneurs.

This is how we identified the first two stages in our natural cycle: primary expansion, generated by a change in the structure of time preferences and expectations (the system becomes more future-oriented), and secondary expansion characterized by imitative investments.

If, therefore, the reality of imitative speculations cannot be eliminated, it outlines the character of the growth process by emphasizing development above the initially imagined level. As for the primary wave of investments, the second wave is also generated by profit expectations, particularly the expectation that the current situation will not change (Schumpeter, 1939, 145). From a quantitative point of view, moreover, imitation (secondary) investments might even be greater than the first cycle of investments since they involve a larger number of individuals, whose expectations are 'over-excited' by the boom (Schumpeter, 1939, 146). These secondary investments will have to be liquidated through an adjustment crisis, as we shall attempt to demonstrate.

The fact that secondary wave investments necessarily bring about their liquidation, by generating a crisis, even if for boom not induced artificially by discoordination between natural and monetary rates, apparently seems to be at odds with the traditional version of the Austrian theory, which does not admit the crisis whenever such discoordination is not at the base of the growth process. We believe, on the other hand, that - while not denying the validity of the Austrian approach - this vision should be superseded. 
Let's summarise the appearance of primary expansion characterising our natural cycle. When, given positive profit expectations, entrepreneurs become more future-oriented, the natural rate of interest grows, in order to move consumer preferences in the same direction, encouraging them to save more and thereby generate resources to meet increased demand for loanable funds by investors. The mirror-image situation arises when consumer expectations change in a more future-oriented direction; in this case, the natural rate of interest falls, informing entrepreneurs that new resources are available for investments in the longer term. Both situations, to use 'Austrian' jargon, give rise to a sustainable boom.

According to this schema, given that the lengthening of the production structure derives from a change in time preferences and market operators are not deceived by a monetary rate inconsistent with the natural rate, current investments will always find available resources to complete the business projects launched. This is precisely because, without the interference of political-monetary authorities, market operators are free to 'reveal themselves' to each other and readjust their scheme of preferences in conformity with the modified situation.

However, we have the distinct impression that this view does not take a fundamental fact into account: the rhythm of investments in real time. The Schumpeterian distinction between primary wave and secondary wave investments in this regard becomes critical. In fact, the initial increase in investments followed by a change in the structure of time preferences does not seem to generate any problem. Whether savings grow or the natural interest rate increases because of profit expectations, the timing of the onset of business ventures is necessarily dictated by the realignment of preferences. When savings increase, in fact, the problem does not arise precisely because the increased resources are the first cause of the reduction of the natural rate and the lengthening of the productive structure its consequence. All the more, if there is increased demand for loanable funds, new resources for investment will not be available until consumers decide to increase their propensity to save, that is, until the intentions of the two groups of players re-align again.

The matter changes when second wave of investments comes into play, generated by the imitative process. It is first and foremost a natural fact, intrinsic to the boom, regardless of its type. Indeed, as Schumpeter emphasized, innovation is never generated as a mass phenomenon; on the contrary, it arises through the initiative of certain 'elect spirits' entrepreneurs - whose essence lies precisely in being able to grasp profit opportunities where others fail to see them ${ }^{49}$. Subsequently, in any case, when the expansion phenomenon is already set in motion - when an opportunity for profit has already been identified and grasped by some people - the prospect of grabbing a slice of the cake becomes tempting for many (the role of expectations). Not for those who have seized the opportunity and, having begun to invest, are now on the way towards reaping their reward; but for those who were bystanders and are now seeking to take part in the boom stage (with a time lapse compared to the primary wave).

What form does the imitative desire take? It generates new demand for loanable funds in order to insert a more roundabout production process into the expansive cycle. This means an attempt to extend the expansion process temporarily, thereby also increasing the degree of uncertainty.

More time taken implies more things can happen - providing the possibility of greater productivity but also greater uncertainty. Since the value of higher order (capital) goods depends on the prospective value of the consumer goods they are expected to produce, the elapse of time, and with it the arrival of unexpected events, implies that some production plans are bound to be disappointed and thus the value of specific capital goods will be affected. (Lewin, 2005, 151). 
And this brings us to the second stage of the natural cycle: secondary expansion. Pressure on demand for loanable funds forces the natural interest rate to rise further, in order to attract new savings to finance these investments. And this is where the role of banks joins the game to a very similar extent to that described by Schumpeter. Initially, demand for loanable funds cannot be met because preferences have not yet realigned with the new interest rate level and it is even likely that such a realignment does not actually take place.

However, the positive sentiment, the positive profit expectations, that become 'incandescent' at the end of the primary expansion stage, also plays a role as regards the action of banks. In fact, precisely because of what happens during expansion, it is highly likely that banks make available 'virtual funds' that are not backed up by real savings (as is the case during the first wave of investments), driven by expectations that the adaptation of consumer preferences (further savings) cannot but occur, precisely because of the enthusiasm generated by the boom.

On the other hand, it is more than likely that the long-awaited realignment does not come about. Even though the natural rate may increase, in view of the profit expectations arising from the request for second wave of investments (imitative), the likelihood that savings may increase is limited by two factors. The most obvious one is of course that consumers must also consume, hence their capacity for saving (and realignment) is objectively limited by the necessity to consume. In addition, in all likelihood, consumers will also be influenced by the general enthusiasm of the boom stage and consequently change their preferences in the opposite direction, i.e. by increasing their propensity for consumption. This is all the more true given the fact that real wages grow during the boom in order to attract workers into the new investment areas or to employ formerly unemployed workers. As in the conventional Austrian explanation, this leads to pressure in demand for consumer goods, with an initial phenomenon of forced savings and the production structure subsequent need to return to present-oriented projects (consumer goods). At this point, the growth of price and wages and the pressure on prices goods of consumer goods brings about what Hayek called the 'Ricardo effect': it helps explain why a prolonged boom stage driven by monetary expansion is likely to turn into a crisis.

[I]f the credit expansion boom does not come to an end sooner for some other reason, it must come to an end when consumer product prices advance ahead of wage and resource prices. The Ricardo effect lowers real wages and encourages a shift toward labor-intensive methods of production. A lowering of the real wage of labor makes short-term (labor-intensive) projects appear to be more profitable than long-term (capital-intensive) methods of production. The Ricardo effect may account for the sudden wave of bankruptcies among the large fixed-investment projects that occurred toward the end of many nineteenth-century business cycles. (Moss, 2005, 8-9).

So, while the first wave of investments can complete its cycle because of the real existence of prior and stable funds (without which the expansion cycle would not even have started), the second wave will be frustrated by a change in consumer preferences and a banking policy influenced by expectations of profit.

The difference between sustainable growth and artificial boom, therefore, lies in the following fact: where the 'defective' cycle is triggered by a discoordination between a natural rate and a monetary rate controlled by the monetary authorities, in general many of the roundabout processes of production end up being frustrated by the onset of the Hayekian phenomenon of scarcity of capital, as described above. On the other hand, for a sustainable boom (natural cycle) generated by a change in expectations, it is only the inevitable wave of speculative-imitative investment, backed up by a banking policy influenced by a positive sentiment, which itself will later be frustrated, wherein a crisis will be the necessary action to liquidate such faulty initiatives. 
What will follow in the latter case will be a crisis (third stage of the natural cycle) but limited in terms of intensity, duration and the number of sectors involved. We could even define it as a transitory readjustment crisis, which does not cancel the beneficial effects of the previous boom but merely liquidates business ventures launched for speculative-imitative purposes. What will not follow, instead, is a fourth stage, the depression, typical of the 'defective' cycle.

\section{OUR TheORY AND THE CURRENT CRISIS}

The crisis emerged in the United States and Europe in 2007 can be described by our theory; first and above all it falls into the category of what we described as unsustainable boom: the production structure becomes more roundabout not because of a modification in the intertemporal structure of preferences, but because of credit policy sending wrong price signals to entrepreneurs.

The quantitative easing igniting the typical Misesian artificial boom is strongly supported by empirical evidences ${ }^{50}$. Table 1 in Ferlito $(2010,40-41)$ shows a distortive monetary policy starting to happen in 2001. From the peak reached in 2000 (6.4\%), the Fed began to lower the official interest rate. We remember that at that time America was facing the difficulties created by the end of the new economy bubble and, later in 2001, by the $9 / 11$ attack. Such an expansionary policy lasted until mid-2004 (i=1\%), when, because of an inflationary dynamics, Fed started to move in the opposite direction. However, interest rates remained below levels suggested by the Tailor rule until 2006. As argued in Taylor (2009), «Fed kept the funds rate below that suggested by the eponymous Taylor rule for 4 years» ${ }^{51}$. Figure 1 summarizes the situation.

Figure 1: Actual Federal funds rate vs. counterfactual Federal funds rate (Koppl, 2014, 23).

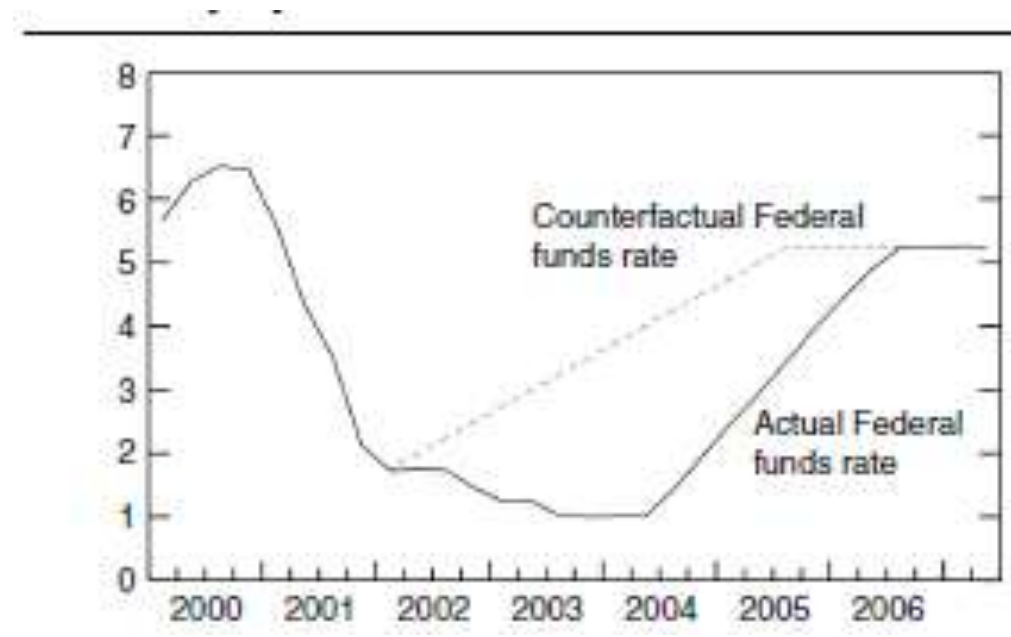

\footnotetext{
${ }^{50}$ See, in particular, Koppl (2014, 18-40), Ahrend (2010), Young (2012) and Bocutoğlu and Ekinci (2010).

${ }^{51}$ Young $(2012,79)$. «The rule advised the Fed to target the short-term interest rate (the federal funds rate). This rate 'should be one-and-a-half times the inflation rate plus one-half times the GDP gap plus one' (Taylor 2009, location 519). In this case, the 'GDP gap' is just 'the percent deviation of real GDP from a target', which he takes to be the trend of 2.2 per cent per year growth that held between 1984 and 1992» (Koppl, 2014, 20). Detailed graph comparing actual rates and 'Taylor' rates country by country can be found in Ahrend (2010, 6-7).
} 
The trend inverted again on July 2007 ( $\mathrm{i}=5.25 \%$ ), after the emergence of the subprime crisis. Since then, official interest rate never stopped to move downward, as it is well known. A similar trend is observable in the ECB interest rate policy, with some time lag and less drastic movements ${ }^{52}$. The expansionary trend of the monetary policy is supported by statistics regarding M3 and $\mathrm{M}^{53}$ and particularly astonishing is the $106 \%$ jump in $\mathrm{M} 0$ in the USA in 2009. Data on American bank credit confirms the easy money trend of the pre-crisis years. According to statistics published by the Federal Reserve of St. Louis, the USA banking system was lending 5,000 billions USD in 2000 and more than double in $2008^{54}$. Moreover, M2 recorded a $32 \%$ growth between $2002-2006^{55}$.

As it is well known, most of the new credit was real-estate credit, financing a bubble in the housing market.

Figure 2: Real-estate/Bus Loans Credits in the United States (\%) (Bocutoğlu and Ekinci, 2010, 12).

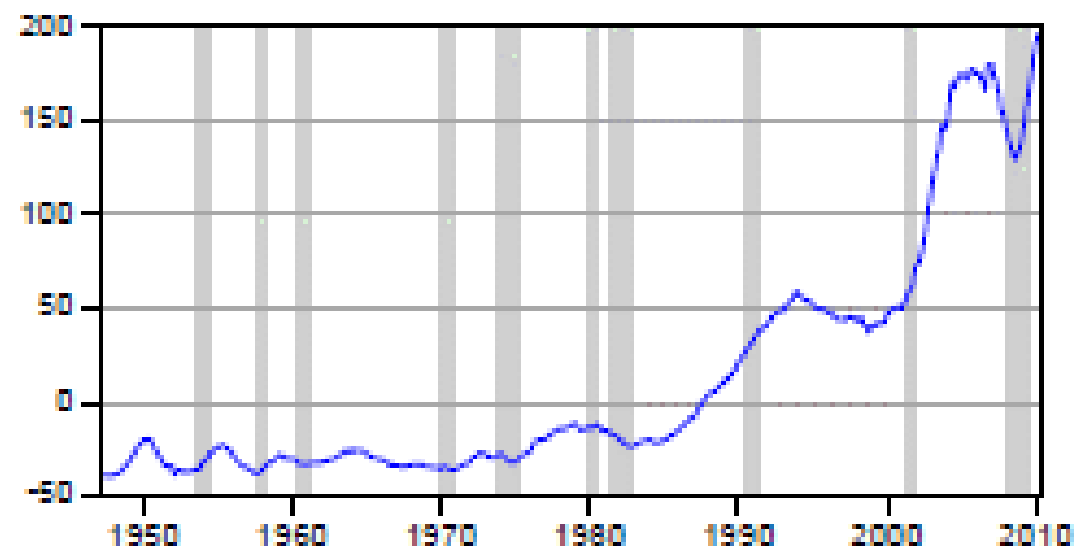

As stated in Taylor (2009), the

effects of the boom and bust were amplified by several complicating factors including the use of subprime and adjustable-rate mortgages, which led to excessive risk taking. There is also evidence the excessive risk taking was encouraged by the excessively low interest rates. Delinquency rates and foreclosure rates are inversely related to housing price inflation. These rates declined rapidly during the years housing prices rose rapidly, likely throwing mortgage-underwriting programs off track and misleading many people ${ }^{56}$.

Figure 3: Total derivative market (TDM) (in trillions) (Bocutoğlu and Ekinci, 2010, 15).

\footnotetext{
${ }^{52}$ Ferlito $(2010,40-41)$

${ }^{53}$ Ferlito (2010, 43).

${ }^{54}$ Ferlito $(2010,44)$.

${ }^{55}$ Koppl $(2014,24)$.

${ }^{56}$ Quoted in Bocutoğlu and Ekinci (2010, 15).
} 


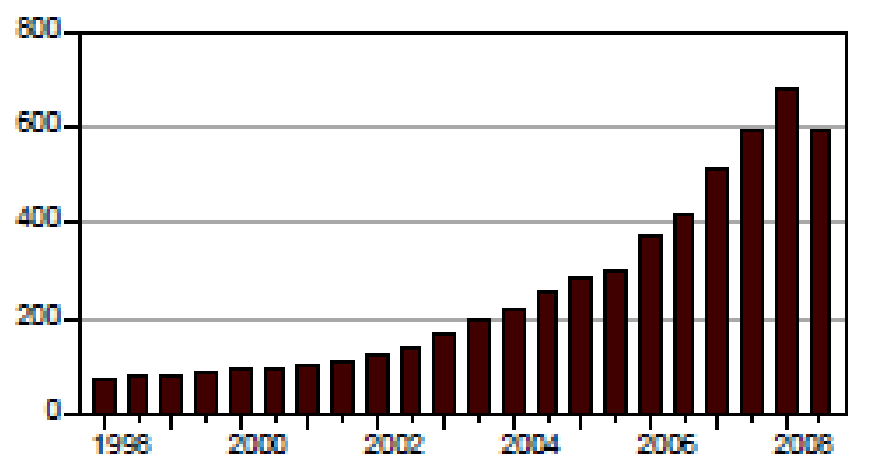

The effect of the monetary expansion is visible on the GDP trend ${ }^{57}$. Europe and USA experienced good rates of GDP growth and a moderate reduction in unemployment between 2002 and 2006. However, the trend proved to be unsustainable, because driven by monetary expansions and not by a change in the intertemporal structure of preferences.

Table 1: Unemployment Rate, Real GDP Growth, and the Federal Funds Rate: 2002-2009 (Young, 2012, 80).

\begin{tabular}{llll}
\hline & Unemployment Rate & Real GDP Growth Rate & Federal Funds Rate \\
\hline 2002 & 5.8 & 1.8 & 1.67 \\
2003 & 6.0 & 2.5 & 1.13 \\
2004 & 5.5 & 3.6 & 1.35 \\
2005 & 5.1 & 3.1 & 3.21 \\
2006 & 4.6 & 2.7 & 4.96 \\
2007 & 4.6 & 1.9 & 5.02 \\
2008 & 5.8 & 0.0 & 1.93 \\
2009 & 9.3 & -2.6 & 0.16 \\
\hline
\end{tabular}

Now that we observed the monetary expansion and the effect on the GDP, it is necessary to check how the production structure and the price dynamics were distorted by such expansion. In the USA, investment in capital goods touched a lower peak in 2002, following the 2001 crisis: around 47 billions USD. Following the monetary expansions, the amount started to rise again to reach 68 billions USD in 2007, when a new downward movement began to go back to 50 billions USD in 2009. The trend is confirmed by the price dynamics: moving upward between 2003 and 2007, starting to fall down after the emergence of the new crisis $^{58}$.

As it is well known, the bubble regarded in particular the property industry, so we should be able to observe an upward trend in prices of property. This is, indeed, the case: while property prices increased by 59\% from the beginning of 1997 to the end of 2001, the rise in housing prices was $83 \%$ in the period from December 2001 to June $2006^{59}$.

Figure 4: Case-Schiller Home Price Index (CS) and effective federal-funds rates (FF)

\footnotetext{
${ }^{57}$ Ferlito $(2010,46)$

${ }^{58}$ Ferlito $(2010,45)$.

${ }^{59}$ Bocutoğlu and Ekinci $(2010,10)$.
} 


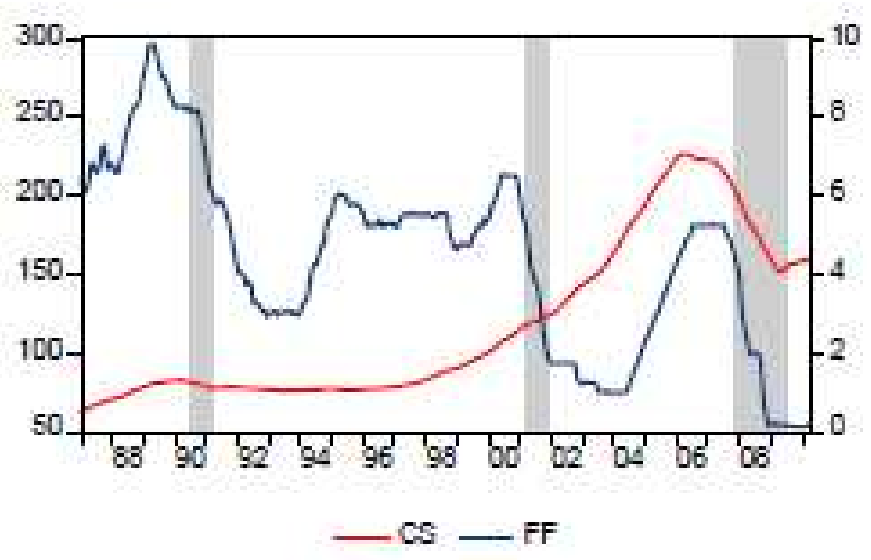

The relation between monetary expansion and housing prices is empirically verified also for a panel of countries by Ahrend $(2010,14)$.

\begin{tabular}{|c|c|c|c|c|c|c|c|}
\hline Canada & 2001-07 & Very strong increase & Very strong increase & Very strong increase & Verystrong increase & Strong increase & Strong increase \\
\hline Denmark & $2001-04$ & Strong increase & Very strong increase & Very strong increase & n.a. & Verystrong increase & Strong increase \\
\hline Australia & $2000-03$ & Very strong increase & Moderate decrease & n.a. & Very strong increase & Strong increase & Moderate decrease \\
\hline Portugal & $1998-2005$ & n.a. & n.a. & Strong increase & ก.a. & n.a. & Strong decrease \\
\hline Spain & 1998-2007 & Very strong increase & Very strong increase & Very strong increase & Very strong increase & n.a. & Strong increase \\
\hline Italy & $1989-2006$ & Strong increase & Strong increase & Very strong increase & Very strong increase & n.a. & Moderate decrease \\
\hline France & 2001-06 & Very strong increase & Very strong increase & Very strong increase & Strong increase & n.a. & Moderate increase \\
\hline Ireland & 1999-2007 & Very strong increase & Very strong increase & Very strong increase & Very strong increase & n.a. & Moderate increase \\
\hline Finland & $2000-02$ & Very strong increase & Strong decrease & n.a. & Strong decrease & n.a. & Very strong decrease \\
\hline us & $1890-83$ & Moderate decrease & Moderate increase & Strong increase & Mbderate decrease & Moderate decrease & Very strong increase \\
\hline Switzerland & $1885-88$ & Verystrong increase & Verystrong increase & Very strong increase & Verystrong increase & Strong increase & Very strong increase \\
\hline Finland & $1987-88$ & Very strong increase (intialy) ${ }^{2 \mid}$ & Very strong increase & n.a. & n.a. & n.a. & Very strong decrease \\
\hline
\end{tabular}

In order to understand the modifications that the production structure experienced because of the credit expansion, we shall refer to the empirical evaluation done by Young (2012, 81-90). In fact, quite uniquely, the author tries to give a quantitative measure of the level of what the ABCT calls 'roundaboutness': because of the monetary expansion, entrepreneurs try to expand early production stages. However, and here we can find the reason why the boom cannot be sustained, consumers do become more future-oriented, they do not change their time preferences and therefore they are still demanding the same consumption goods. Entrepreneurs try to make longer the production structure, while consumers want to preserve it as it is.

Young (2012) uses the total industry output requirement (TIOR) in order to measure the roundaboutness of the production processes.

The TIOR is, for a given industry, "the output required, both directly and indirectly, by each [other] industry to deliver a dollar of final demand of industry output to final users." In other words, it is the amount of gross output from other industries that must be produced per dollar of a given industry's output: the ratio of total gross output to final output for an industry. This ratio will be greater than unity by definition. The critical assumption of this study is that an industry's roundaboutness is proportional to its TIOR. (Young, 2012, 81-82).

Typical, Austrian economics considers production process as divided into a series of stages, $i=1, \ldots, N$. The initial amount of input is called $X_{0}$. At each stage, the gross output will 
be $X_{\mathrm{i}}$, where $X_{\mathrm{i}}=X_{\mathrm{i}-1}+(\text { value-added })_{\mathrm{i}}$. The final gross output $X_{N}$ is $X_{N}=\sum_{i=1}^{N} X \mathrm{i}$. At each stage, TIOR $=X / X_{N}$. Young $(2012,82-83)$ summarizes this in the following table.

Table 2: Value-Added, Gross Output, and TIOR (Young, 2012, 83).

\begin{tabular}{lllll}
\hline Stage & Value-Added & Gross Output & Total Gross Output & T1OR \\
\hline 1 & 100 & 100 & 100 & 1 \\
2 & 10 & 110 & 220 & 2 \\
3 & 11 & 121 & 341 & 2.81 \\
4 & 12 & 133 & 474 & 3.56 \\
5 & 13 & 146 & 610 & 4.17 \\
\hline
\end{tabular}

An economic system becoming more roundabout is, i.e., an economic system moving from having four stages and therefore producing 474 with a TIOR of 3.56 to recording five stages and producing 610 with TIOR=4.17. Young (2012) collected TIORs for 65 industries for the years 1998 to 2009. With such data a measure of roundaboutness was built, weighing each industry using the shares of total value added. The aim was to check if the production structure changed during the period 2002-2006. Results are shown in the below figure.

Figure 5: US Aggregate Roundaboutness and Federal Funds Rate, 1998-2009 (Young, 2012, 85).

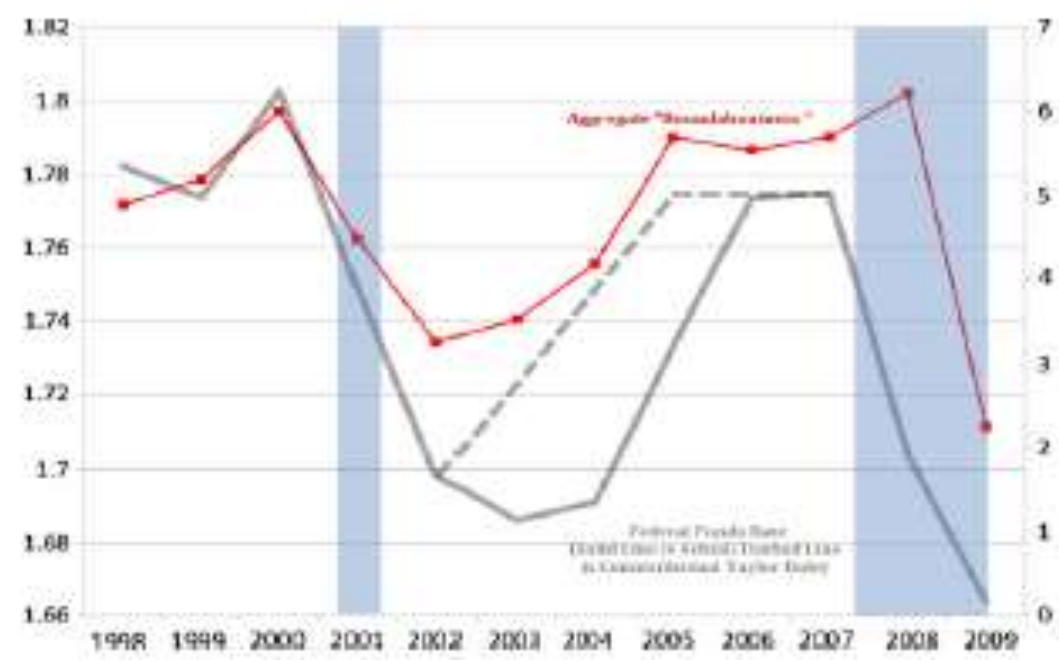

Figure 5 shows that

[h] eading into the 2001 recession, the aggregate TIOR was falling. Then in 2002, following the recession, and precisely when the Federal Reserve embarked on an exceedingly expansionary policy (by the Taylor rule standard), the aggregate TIOR began to expand at an increasing rate. The TIOR levels off and then rises only slowly following the Fed's (belated) increases of the funds rate starting in 2004.

The 2007 to 2009 recession was then characterized by a remarkable decrease in the aggregate TIOR, indicating a contraction of the time structure of production. While the aggregate TIOR low following the 2001 recession was just under 1.74, the last observation available for the TIOR (in 2009) is about 1.71. (Young, 2012, $85)$.

Subsequently, Young $(2012,86-87)$ divided industries in two group, the more roundabout (MR) and the less roundabout (LR). According to the theory described in section 4, we 
should expect that MR and LR registered both a growth during the artificial boom (20022006). But we should expect that MR industries grew earlier and at a heavier pace, while the LR industries peak should arrive later. At the same time, the growth for MR industries should turn negative earlier. This is what indeed happened.

While coming out 2002 the (average) growth rates of value-added in both MR and LR industry subsamples increased, value-added growth in MR industries accelerated markedly, peaking at about 11.7 percent in 2004. Value-added growth in LR industries also accelerated during the boom, but the acceleration was more muted and peaked later (at about 7.5 percent in 2005). MR value-added growth also contracted relatively early, turning negative in 2007. LR value-added growth remained positive until 2009. Notably, the timing of the peak in MR value-added growth coincided with the Fed beginning to increase the federal funds rate in 2004. (Young, 2012, 86).

Figure 6: Value-Added Growth Rates for Most and Least Roundabout Industries; Federal Funds Rate, 1998-2009 (Young, 2012, 88.

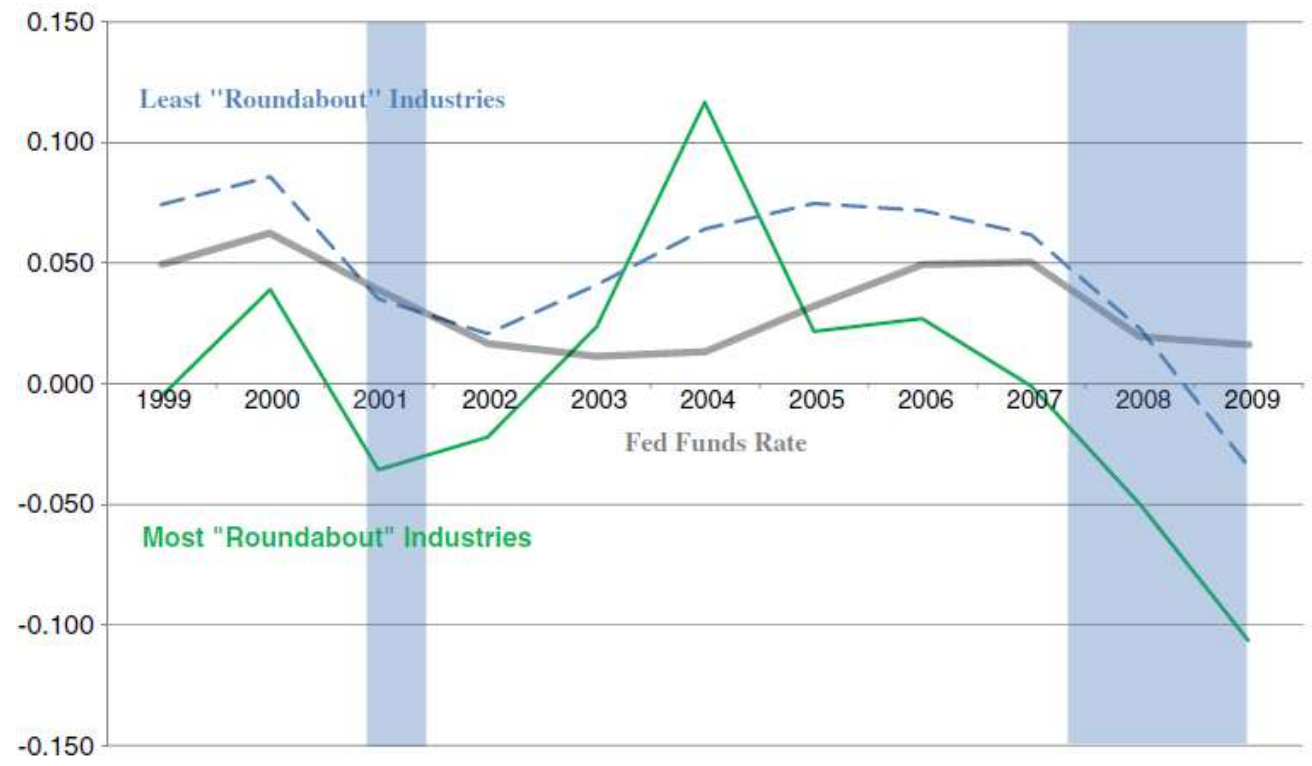

Such a dynamics should find a counterpart in the inflationary trend. If the theory is consistent, we expect to find inflation for MR industries during the 'hottest' years of the boom (2002-2004). On the contrary, price dynamics for LR industries should manifest less intense variations. Again, such conclusions are confirmed by Young statistical investigation.

The LR (average) industry inflation rate was relatively stable from 1999 to 2009. A slow acceleration (consistent with ABCT) did occur from 2002 through 2006, followed by a subsequent decrease in PPI inflation. For the MR industries a remarkable acceleration in PPI inflation (peaking in 2004) accompanied the corresponding nominal value-added boom (Fig. 3). Moreover, the MR inflation rate in 2004 was greater than the value-added growth rate (15.6 percent versus 11.7 percent). (Young, 2012, 88).

Figure 7: PPI Average Inflation Rates for Most and Least Roundabout Industries, 1998-2009 (Young, 2012, 89). 


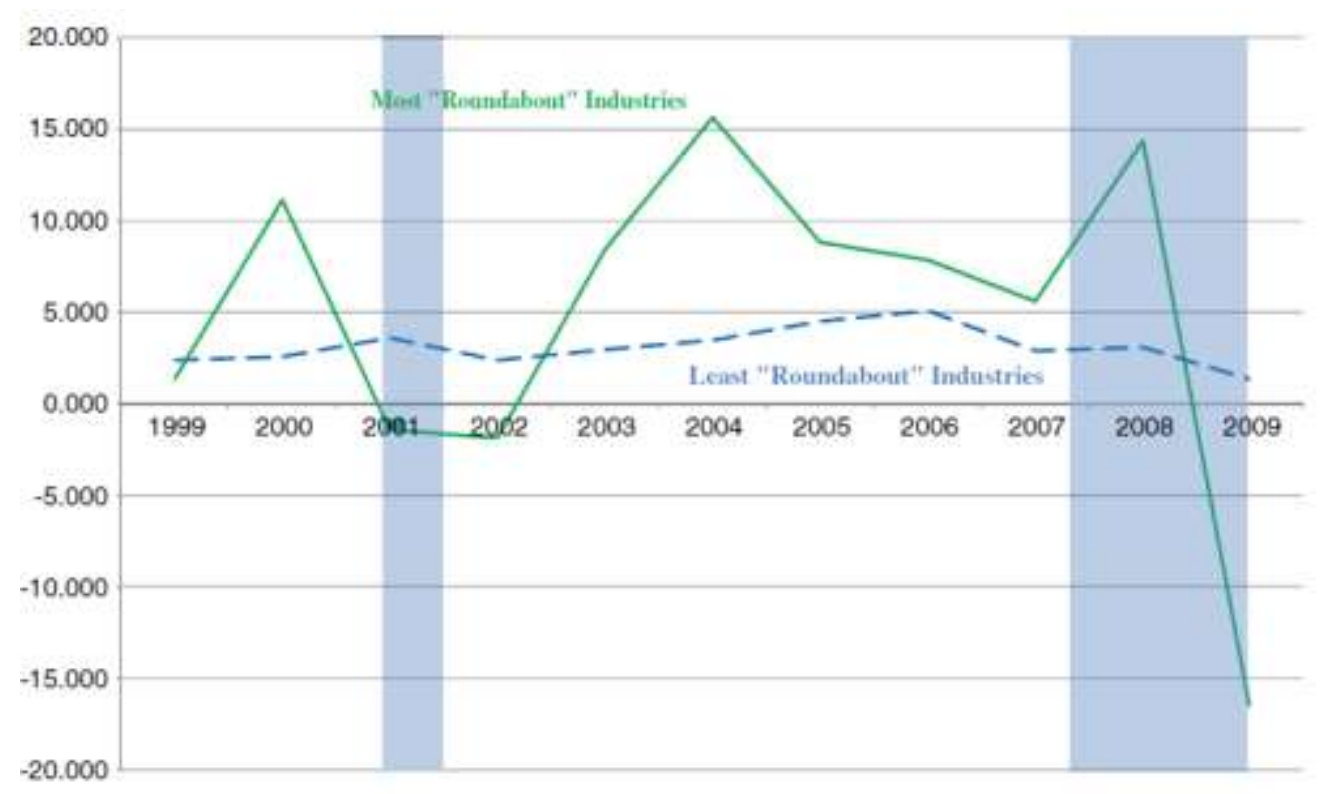

Finally, we shall try to distinguish what happened with the unsustainable boom and what could had happened in case of natural cycle. Or, better, we should look at the two stages of the growth path (primary and secondary waves), which, according to our vision, are experienced in both cases. And, instead, we should identify crisis and depression in the unsustainable case, while in case of natural cycle the downturn movement should have been less severe. In fact, what we claimed, following Schumpeter, is that all the booms (ignited by monetary easing or by more future-oriented expectations) are characterized by two stages: the initial growth and the speculative wave (fever). In the case of inflation induced boom we should then experience a longer a deeper crisis than in case of natural cycle.

Eurostat and Federal Reserve Bank of St. Louis support our idea that the boom should be divided into two stages.

Table 3: GDP USA (trillions of USD) and EU-15 (billions of EURO), 2001-2014 (Federal Reserve bank of St. Louis and Eurostat).

\begin{tabular}{|c|c|c|c|c|}
\hline Date & GDP USA & $\mathbf{\% \Delta ~ o n ~ Y - 1 ~}$ & GDP EU-15 & $\% \mathbf{\Delta ~ o n ~ Y - 1 ~}$ \\
\hline $2001-01-01$ & USD 10,508.10 & & EUR 9,082,627.20 & \\
\hline $2002-01-01$ & USD 10,834.40 & $3.11 \%$ & EUR 9,418,817.40 & $3.70 \%$ \\
\hline $2003-01-01$ & USD 11,230.10 & $3.65 \%$ & EUR 9,750,628.90 & $3.52 \%$ \\
\hline $2004-01-01$ & USD 11,988.40 & $6.75 \%$ & EUR 9,922,512.10 & $1.76 \%$ \\
\hline $2005-01-01$ & USD 12,813.70 & $6.88 \%$ & EUR 10,395,107.00 & $4.76 \%$ \\
\hline $2006-01-01$ & USD 13,648.90 & $6.52 \%$ & EUR 10,782,958.70 & $3.73 \%$ \\
\hline $2007-01-01$ & USD 14,233.20 & $4.28 \%$ & EUR 11,361,207.80 & $5.36 \%$ \\
\hline $2008-01-01$ & USD 14,668.40 & $3.06 \%$ & EUR 11,964,559.40 & $5.31 \%$ \\
\hline $2009-01-01$ & USD 14,383.90 & $-1.94 \%$ & EUR 11,925,489.60 & $-0.33 \%$ \\
\hline $2010-01-01$ & USD 14,681.10 & $2.07 \%$ & EUR 11,303,488.80 & $-5.22 \%$ \\
\hline $2011-01-01$ & USD 15,238.40 & $3.80 \%$ & EUR 11,777,522.40 & $4.19 \%$ \\
\hline $2012-01-01$ & USD 15,973.90 & $4.83 \%$ & EUR 12,113,108.60 & $2.85 \%$ \\
\hline $2013-01-01$ & USD 16,440.70 & $2.92 \%$ & EUR 12,347,726.10 & $1.94 \%$ \\
\hline $2014-01-01$ & USD 16,984.30 & $3.31 \%$ & EUR 12,425,758.80 & $0.63 \%$ \\
\hline $2015-01-01$ & USD 17,649.30 & $3.92 \%$ & EUR 12,795,712.20 & $2.98 \%$ \\
\hline
\end{tabular}

Table 3 shows that the boom started, both in America and in Europe, with growth rates between 3 and 4\%. It is only in 2004 that the USA economy starts to grow at an annual pace close to $7 \%$. In Europe it is visible the same dynamics, though slightly later and at a lower 
pace. Growth remains around $4 \%$ for the greatest part of the expansion, while we can talk of a secondary and speculative fever only in 2006 and 2007. What is important is that in both continents we can clearly distinguish a moment of initial expansion (first wave of the boom), stably running at around $3.5 \%$ a year, and a strong secondary boom with rates well above $6.5 \%$ in the USA and around $5.5 \%$ in the EU. On the Western side of the Atlantic Ocean the first wave of expansion lasted only two years to give way to an early secondary wave, lasting three years, which gradually turn off (two years) before reaching the crisis. In Europe, instead, we see a primary wave lasting five years, before the entering of the secondary boom (two years) which ended directly into the crisis.

Such dynamics is confirmed by data on house pricing in the USA.

Table 4: HPI indexes, USA, 2001-2015.

\begin{tabular}{|c|c|c|c|c|}
\hline Year & Quarter & $\begin{array}{c}\text { Purchase-Only Index } \\
(1991 Q 1=100)\end{array}$ & $\begin{array}{c}\text { HPI } \\
\text { \% Change Over } \\
\text { Previous } 4 \text { Quarters }\end{array}$ & $\begin{array}{c}\text { HPI } \\
\text { \% Change Over } \\
\text { Previous Quarter }\end{array}$ \\
\hline 2001 & 1 & 146.57 & $7.66 \%$ & $2.46 \%$ \\
\hline 2001 & 2 & 150.16 & $7.71 \%$ & $1.68 \%$ \\
\hline 2001 & 3 & 152.68 & $7.43 \%$ & $1.55 \%$ \\
\hline 2001 & 4 & 153.98 & $7.11 \%$ & $1.24 \%$ \\
\hline 2002 & 1 & 156.13 & $6.04 \%$ & $1.44 \%$ \\
\hline 2002 & 2 & 160.37 & $6.06 \%$ & $1.69 \%$ \\
\hline 2002 & 3 & 163.75 & $6.51 \%$ & $1.99 \%$ \\
\hline 2002 & 4 & 165.80 & $6.70 \%$ & $1.42 \%$ \\
\hline 2003 & 1 & 168.18 & $6.47 \%$ & $1.22 \%$ \\
\hline 2003 & 2 & 172.46 & $5.97 \%$ & $1.22 \%$ \\
\hline 2003 & 3 & 176.21 & $5.49 \%$ & $1.53 \%$ \\
\hline 2003 & 4 & 178.82 & $6.95 \%$ & $2.82 \%$ \\
\hline 2004 & 1 & 182.18 & $7.31 \%$ & $1.56 \%$ \\
\hline 2004 & 2 & 188.58 & $8.60 \%$ & $2.43 \%$ \\
\hline 2004 & 3 & 193.81 & $11.05 \%$ & $3.82 \%$ \\
\hline 2004 & 4 & 196.96 & $10.30 \%$ & $2.13 \%$ \\
\hline 2005 & 1 & 201.10 & $11.11 \%$ & $2.30 \%$ \\
\hline 2005 & 2 & 208.64 & $11.94 \%$ & $3.19 \%$ \\
\hline 2005 & 3 & 214.39 & $11.06 \%$ & $3.01 \%$ \\
\hline 2005 & 4 & 217.04 & $11.21 \%$ & $2.26 \%$ \\
\hline 2006 & 1 & 219.51 & $10.44 \%$ & $1.60 \%$ \\
\hline 2006 & 2 & 223.77 & $8.12 \%$ & $1.03 \%$ \\
\hline 2006 & 3 & 224.52 & $5.84 \%$ & $0.84 \%$ \\
\hline 2006 & 4 & 223.56 & $4.55 \%$ & $1.02 \%$ \\
\hline 2007 & 1 & 224.02 & $3.30 \%$ & $0.38 \%$ \\
\hline 2007 & 2 & 226.56 & $2.18 \%$ & $-0.06 \%$ \\
\hline 2007 & 3 & 223.97 & $0.22 \%$ & $-1.10 \%$ \\
\hline 2007 & 4 & 218.00 & $-1.07 \%$ & $-0.28 \%$ \\
\hline 2008 & 1 & 211.79 & $-2.12 \%$ & $-0.69 \%$ \\
\hline 2008 & 2 & 209.16 & $-4.48 \%$ & $-2.47 \%$ \\
\hline 2008 & 3 & 204.25 & $-6.42 \%$ & $-3.11 \%$ \\
\hline 2008 & 4 & 196.23 & $-6.99 \%$ & $-0.89 \%$ \\
\hline 2009 & 1 & 194.09 & $-5.65 \%$ & $0.75 \%$ \\
\hline
\end{tabular}




\begin{tabular}{|l|l|l|l|l|}
\hline 2009 & 2 & 194.64 & $-5.82 \%$ & $-2.65 \%$ \\
\hline 2009 & 3 & 193.81 & $-5.37 \%$ & $-2.65 \%$ \\
\hline 2009 & 4 & 191.69 & $-5.20 \%$ & $-0.71 \%$ \\
\hline 2010 & 1 & 188.13 & $-7.03 \%$ & $-1.20 \%$ \\
\hline 2010 & 2 & 190.92 & $-5.34 \%$ & $-0.88 \%$ \\
\hline 2010 & 3 & 187.91 & $-1.82 \%$ & $0.97 \%$ \\
\hline 2010 & 4 & 183.85 & $-1.82 \%$ & $-0.71 \%$ \\
\hline 2011 & 1 & 178.08 & $-3.37 \%$ & $-2.76 \%$ \\
\hline 2011 & 2 & 180.57 & $-4.15 \%$ & $-1.68 \%$ \\
\hline 2011 & 3 & 181.65 & $-4.32 \%$ & $0.80 \%$ \\
\hline 2011 & 4 & 179.67 & $-3.18 \%$ & $0.47 \%$ \\
\hline 2012 & 1 & 179.02 & $-1.46 \%$ & $-1.03 \%$ \\
\hline 2012 & 2 & 186.34 & $-0.13 \%$ & $-0.35 \%$ \\
\hline 2012 & 3 & 188.65 & $0.36 \%$ & $1.30 \%$ \\
\hline 2012 & 4 & 189.10 & $0.71 \%$ & $0.82 \%$ \\
\hline 2013 & 1 & 191.35 & $2.30 \%$ & $0.53 \%$ \\
\hline 2013 & 2 & 200.08 & $4.32 \%$ & $1.62 \%$ \\
\hline 2013 & 3 & 203.92 & $4.69 \%$ & $1.66 \%$ \\
\hline 2013 & 4 & 203.32 & $4.88 \%$ & $1.00 \%$ \\
\hline 2014 & 1 & 204.34 & $5.30 \%$ & $0.93 \%$ \\
\hline 2014 & 2 & 211.18 & $5.87 \%$ & $2.17 \%$ \\
\hline 2014 & 3 & 213.65 & $5.76 \%$ & $1.54 \%$ \\
\hline 2014 & 4 & 213.58 & $5.63 \%$ & $0.87 \%$ \\
\hline 2015 & 1 & 215.10 & $5.56 \%$ & $0.87 \%$ \\
\hline 2015 & 2 & 222.58 & $5.25 \%$ & $1.86 \%$ \\
\hline & & & & \\
\hline
\end{tabular}

Table 4 testifies that because of the 2001 new economy crisis houses prices slowed their growth path in 2002 and 2003, recording an annual average growth around 6\%. It is from 2004 that we can see, accordingly to what we could expect, the rate of annual growth speed up to $10-12 \%$. As for the GDP we observe a moderation in 2007 , after three speculative years (2004-2006). Toward the end of 2007, with the emergence of the economic crisis, housing prices starts gradually to fall down, to start to rise again in the third quarter of 2012.

Our considerations about the existence of two waves in the boom is therefore confirmed by GDP and housing prices dynamics. It is more difficult, instead, to reach definitive conclusions regarding the recession. When would the downturn stop if instead of an artificially ignited expansion we had experienced a growth driven by rising profit expectations met by a growing saving rate? It is hard to say, in particular because QEs did not allow the deflationary process to take the necessary course in order to definitely clear the field from the results of malinvestments ${ }^{60}$. GDP data do not adequately testify the intensity of the crisis and the structural process of readjustment toward a new production structure consistent with the intentions of consumers and investors. However, we can observe that the years after the crisis are characterized by slow growth and, moreover, high unemployment. Data on housing prices show the struggle in the industry that led the boom. The point in our analysis on the natural cycle is that, if such a case would occur, the system would not need to struggle to go back to the production structure typical of the years preceding the boom (long readjustment process). Instead, what the system would need to clear out would be only the results of the years of the secondary wave, the speculative one. We could imagine, thus, a

${ }^{60}$ See Ferlito (2014b). 
shorter readjustment process affecting only a smaller number of companies; low growth performances should last for a limited period and unemployment should set at a lower level. Such conclusions are based, of course, on the hypothesis of absence if manipulations by the central banks and the banking system in general.

\section{Conclusions}

The analysis developed so far allows us to conclude, in a very simple way and in the wake of authoritative economists of the past, that the cyclical trend is the form that development takes in a capitalist economy.

While acknowledging the basic assumptions of the Austrian business cycle theory as valid, especially in Hayek's version, we must also recognize that it does not suffice to eliminate the Central Bank and its 'deceptive' role exerted through the monetary interest rate in order to annihilate the cyclical dynamics of development.

The systematic introduction of 'real' expectations, acting in 'real time', in the sense advocated by Ludwig Lachmann, can only lead us towards the rediscovery of secondary investment waves (imitations and speculations) on which, in particular, Schumpeter focused. In being made possible by a banking policy sensitive to and part of the general positive sentiment of an expansion stage, they precisely match that part of the growth stage that has to be liquidated through a readjustment crisis.

We therefore believe that the Austrian distinction between sustainable and unsustainable growth is valid. What we rather seek to overcome is the belief that, in the first case, the expansion stage is not followed by a crisis. On the contrary, a liquidation crisis occurs in both cases. The difference lies in the intensity and duration of the crisis. Most of the long-term entrepreneurial projects initiated by entrepreneurs will struggle to be completed in the case of a boom generated from the outset in an 'unhealthy' manner. For growth set in motion in a 'sustainable' manner, only the imitative and speculative initiatives will not be completed. Inasmuch, the positive effects of the first part of the expansion will not be eliminated. It is merely a question of 'clearing up'. We call this instance the natural cycle. In the previous case, on the other hand, reconstruction will have to begin from a pile of rubble.

What the Western world started to experience in 2007 is a typical unsustainable boom, ignited by artificial monetary expansion. Quantitative evidences support the conclusion, including the modification of the production structure. Moreover, two separate parts of the boom (the initial one and the speculative one) are clearly observable. Finally, our framework allows us to claim that crisis typical of a natural cycle would ended earlier and after a less severe readjustment process. 


\section{REFERENCES}

Ahrend, R., 2010, 'Monetary ease: a factor behind financial crises? Some evidence from OECD countries', Economics: The Open Access, Open Assessment E-Journal 4, 12, 14 April.

Bocutoğlu, E. and Ekinci, A., 2010, 'Austrian Business Cycle Theory and Global Financial Crisis: Some Lessons for Macroeconomic Risk and Financial Stability', paper presented at the ICE-TEA 2010: The Global Economy After the Crisis: Challenges and Opportunities, September 1-3.

Borio, C., 2012, 'The financial cycle and macroeconomics: What have we learnt?', BIS Working Papers No 395.

Calvo, G., 2013, 'Puzzling over the anatomy of crises: Liquidity and the Veil of Finance', Background paper for the Mayekawa Lecture at the Institute for Monetary and Economic Studies Conference, Bank of Japan, May 29-30, Tokyo, Japan.

Fanno, M., 1931, 'Production Cycles, Credit Cycles and Industrial Fluctuations', in Business Cycle Theory. Selected Texts 1860-1939, II, Structural Theories of the Business Cycle, edited by H. Hagemann. London: Pickering and Chatto, 2002, 225-261.

Ferlito, C.,. 2007, ‘Bolla immobiliare: dove sono gli economisti?’, Rinascita, 11 august, 16.

Ferlito, C., 2010, Dentro la crisi. Combattere la crisi, difendere il mercato, Chieti: Solfanelli.

Ferlito, C., 2011, 'Sylos Labini's Unpublished Notes on Schumpeter's Business Cycles', The Quarterly Journal of Austrian Economics, 14 (1), 88-129.

Ferlito, C., 2013, Phoenix Economics. From Crisis to Renascence, New York: Nova Publishers.

Ferlito, C., 2014a, 'The Natural Cycle: Why Economic Fluctuations are Inevitable. A Schumpeterian Extension of the Austrian Business Cycle Theory', Journal of Reviews on Global Economics, 3, 200-219.

Ferlito, C., 2014b, 'ECB and the fear of deflation', The Malaysian Insider, 14 April.

von Hayek, F.A., 1929, Monetary Theory and the Trade Cycle (1966 edition), New York: Kelley.

von Hayek, F.A., 1931, Prices and Production (1967 edition), New York: Kelley.

von Hayek, F.A., 1932, 'A Note on the Development of the Doctrine of "Forced Saving", Quarterly Journal of Economics, XLVII, 123-133.

von Hayek, F.A., 1933, 'Price Expectations, Monetary Disturbances and Malinvestments', in Profits, Interest and Investment and Other Essays on the Theory of Industrial Fluctuations, Clifton: Augustus M. Kelley, 1975, 135-156. 
von Hayek, F.A., 1939, 'Profits, interest and Investment', in Profits, Interest and Investment and Other Essays on the Theory of Industrial Fluctuations, Clifton: Augustus M. Kelley, 1975, 3-71.

Huerta de Soto, J., 1998, Money, Bank Credit, and Economic Cycles (2006 edition), Auburn: Ludwig von Mises Institute.

Huerta de Soto, J., 2000, The Austrian School. Market Order and Entrepreneurial Creativity (2010 edition), Cheltenham and Northampton: Edward Elgar.

Hülsmann, J.G., 2013, Krise der Inflationskultur. Geld, Finanzen und Staat in Zeiten der Kollektiven Korruption, Munich, Finanzbuch Verlag, 2013.

Kirzner, I.M., 1973, Competition \& Entrepreneurship, Chicago: University of Chicago Press.

Koopl, R., 2014, From Crisis to Confidence. Macroeconomics after the Crash, London: The Institute of Economic Affairs.

Krugman, P., 2008, The Return of Depression Economics and the Crisis of 2008, New York: W.W. Norton \& Company.

Kurz, H.D., 2003, 'Friedrich August Hayek: la teoria monetaria del sovrainvestimento', in Friedrich A. von Hayek e la Scuola Austriaca di Economia, edited by U. Ternowetz, Soveria Mannelli: Rubbettino, 175-207.

Lachmann, L.M., 1940, 'A Reconsideration of the Austrian Theory of Industrial Fluctuations', in Capital, Expectations, and the Market Process, Kansas City: Sheed Andrews and McMeel, 1977, 267-286.

Lachmann, L.M., 1943, 'The Role of Expectations in Economics as a Social Science', in Capital, Expectations, and the Market Process, Kansas City: Sheed Andrews and McMeel, 1977, 65-80.

Lachmann, L.M., 1956, Capital and Its Structure (1978 edition), Kansas City, Sheed Andrews and McMeel.

Lachmann, L.M, 1976, 'From Mises to Shackle: An Essay on Austrian Economics and the Kaleidic Society', Journal of Economic Literature, 14 (1), 54-62.

Lachmann, L.M., 1982, 'Why Expectations Matter', in Modern Austrian Economics. Archaeology of a Revival, I, A Multi-Directional Revival, edited by S. Gloria-Palermo, London: Pickering and Chatto, 2002, 251-269.

Lachmann, L.M., 1986, The Market as Economic Process, Oxford: Basil Blackwell.

Leijonhufvud, A., 2009, 'Out of the corridor: Keynes and the crisis', Cambridge Journal of Economics, 33, 741-757.

Lewin, P., 1997, 'Capital in Disequilibrium: A re-examination of the capital theory of Ludwig M. Lachmann', unpublished draft. 
Lewin, P., 2005, 'The Capital Idea and the Scope of Economics', The Review of Austrian Economics, 18 (2), 145-167.

Moss, L.S., 2005, 'The applied economics of the modern Austrian School', in Modern Applications of Austrian Thought, edited by J.G. Backhaus, London and New York: Routledge, 3-19.

O'Driscoll, G. and Rizzo, M.J., 1985, The Economics of Time and Ignorance (2002 edition), London and New York: Routledge.

Rizzo, M.J., 1979. 'Disequilibrium and All That: An Introductory Essay', in Time, Uncertainty, and Disequilibrium. Exploration of Austrian Themes, edited by M.J. Rizzo, Lexington: Heath and Company, 1-18.

Roncaglia, A., 2010, Economisti che sbagliano. Le radici cultruali della crisi, Roma-Bari: Laterza.

Rothbard, M.N., 1969, Economic Depressions: Their Cause and Cure (2009 edition), Auburn: Ludwig von Mises Institute.

Sachs, J., 2010, 'La terza via tra Keynes e i tagli', Il Sole 24 Ore, 9 June, 20.

Salerno, J.T., 2012, 'A Reformulation of Austrian Business Cycle Theory in Light of the Financial Crisis', The Quarterly Journal of Austrian Economics, 15 (1), 3-44.

Schumpeter, J.A., 1911, The Theory of Economic Development (1983 edition), New Brunswick and London: Transaction Publishers.

Schumpeter, J.A. 1939, Business Cycles: A Theoretical, Historical and Statistical Analysis of the Capitalist Process (2005 edition), Chevy Chase and Mansfield Centre: Bartleby's Books and Martino Publishing.

Schumpeter, J.A., 1964, Business Cycles. A Theoretical, Historical and Statistical Analysis of the Capitalist Process (2008 abridged Edition), edited by Rendigs Fels, digital edition, un document produit en version numérique par Didier Lagrange.

Shackle, G.L.S., 1972, Epistemics and Economics: A critique of economic doctrines (2009 edition), New Brunswick and London: Transaction Publishers.

Spiethoff, A., 1925, 'Business Cycles', in Business Cycle Theory. Selected Texts 1860-1939, II, Structural Theories of the Business Cycle, edited by H. Hagemann, London: Pickering and Chatto, 2002, 109-205.

Sylos Labini, P., 1954, 'Il problema dello sviluppo economico in Marx e Schumpeter', in Problemi dello sviluppo economico, Bari: Laterza, 1977, 19-73.

Sylos Labini, P., 1984, The Forces of Economic Growth and Decline, Cambridge and London: MIT Press. 
Taylor, J.B., 2009, Getting off track: How government actions and interventions caused, prolonged, and worsened the financial crisis, Stanford: Hoover Institution Press.

Young, A.T., 2012, 'The time structure of production in the US, 2002-2009', The Review of Austrian Economics, 25, 77-92. 